\title{
Adaptive Dynamic Surface Integral Sliding Mode Fault-Tolerant Control for Multimachine Excitation Systems with SVC
}

\author{
Guoqiang Zhu $\mathbb{D}^{1,2}$ Shuang Ji, ${ }^{1,2}$ Zhiwei Li $\mathbb{D}^{1,2}$ and Yilong Zhang ${ }^{1,2}$ \\ ${ }^{1}$ School of Automation Engineering, Northeast Electric Power University, Jilin, China \\ ${ }^{2}$ Jilin Province International Research Center of Precision Drive and Intelligent Control, Jilin, China \\ Correspondence should be addressed to Zhiwei Li; zhiwei.li@neepu.edu.cn
}

Received 2 May 2020; Revised 20 July 2020; Accepted 21 September 2020; Published 4 November 2020

Academic Editor: Sergey Dashkovskiy

Copyright ( 92020 Guoqiang Zhu et al. This is an open access article distributed under the Creative Commons Attribution License, which permits unrestricted use, distribution, and reproduction in any medium, provided the original work is properly cited.

In this paper, an adaptive dynamic surface integral sliding mode fault-tolerant controller is designed for the multimachine power system with static var compensator (SVC) to overcome the problem of actuator failure. The main features of the proposed method are as follows: (1) By combining the dynamic surface control (DSC) method with integral sliding mode (ISM), the tracking errors of the system converge to the neighborhood of zero within a finite time, and the convergence speed, tracking accuracy, and antiinterference ability of the system are also significantly improved. (2) By introducing the failure factors, an adaptive fault-tolerant controller is designed to ensure the stability of the entire system after partial failure of the actuator. (3) By estimating the norm of the ideal weight vector of the radial basis function neural networks (RBFNNs), the computational burden of the controller is reduced. Finally, the simulation results show the effectiveness of the proposed control scheme.

\section{Introduction}

The modern power system has the characteristics of large power grid, large unit, ultrahigh voltage, long distance power transmission, and high automatic control, which brings about great challenges to the stability operation of the power system [1-4]. The important role of generator excitation control in improving the stable operation of the power system has attracted widespread attention from researchers worldwide [5-8]. The traditional power system stabilizer (PSS) $[9,10]$ and linear optimal excitation control [11] are based on the approximate linearization model. Although the small disturbance stability problem can be improved, the effective suppression of large disturbances cannot be achieved. Moreover, due to parameter uncertainty, external interference, multidimensional and strong coupling, and strong nonlinear characteristics, designing a control system is a very challenging task. Therefore, advanced control strategies such as backstepping [12-15], sliding mode variable structure [16-18], and feedback linearization [19] have been proposed to solve the problem of power system excitation control.
The adaptive backstepping technique can effectively handle the case where the parameters are unknown [20-22]. In [20], the infinite bus voltage and transmission line parameters of the single-machine infinite-bus (SMIB) power system are regarded as unknown, and an adaptive backstepping controller is proposed. A robust nonlinear adaptive backstepping excitation controller is designed in [21] by considering the influence of external disturbance based on the parameter uncertainty. However, the problem of "explosion of complexity" exists in the backstepping method. In order to solve this problem, the dynamic surface control method is used [23-27]. In [24], for a class of uncertain nonlinear systems with asymmetric dead zone nonlinearity, an antidisturbance dynamic surface control scheme is proposed, which effectively solves the problems of nonmatching external disturbance and unknown asymmetric dead zone nonlinearity. A first-order filter is introduced on the traditional backstepping method for the power system, and the controller based on the dynamic surface method is designed in [26]. The device effectively improves the stability of the power system. For large-scale multimachine systems with static var compensator (SVC), the decentralized 
dynamic surface quantization control scheme is proposed in [4] and the fuzzy dynamic surface sliding mode controller is designed in [7], which improves the robustness of the system. The partial feedback linearization (PFBL) technique is widely used in the design of excitation control systems by overcoming the limitations of direct feedback linearization (DFBL) and exact feedback linearization (EFBL) on rotor angle measurement problem. In [28], the nonlinear system model is transformed into a reduced-order linear part and a nonlinear dynamic autonomous part. The optimal control theory is used to design a linear state feedback stability controller for the reduced-order linear part, which enhances the transient stability limit of the power system.

However, the feedback linearized excitation controller has a parameter sensitivity problem. Sliding mode control (SMC) overcomes the parameter sensitivity problem due to being less sensitive to changes in parameters and external disturbances [29-34]. In [35], for the multimachine power system with external disturbance, the adaptive method and the sliding mode variable structure method are combined based on the feedback linearization to design a decentralized coordinated adaptive sliding mode stabilizer. The adaptive gain of the super-twist algorithm is constructed by using the equivalent control theory, and the finite time stability of the closed-loop power system is realized in [33]. In [36], by combining adaptive fuzzy control with sliding mode control, the chattering problem caused by system uncertainty and dynamics is overcome, and the tracking error is converged to zero better and faster. In addition, intelligent controllers [37-43] are also widely used. The fuzzy logic rules [40] and the neural networks $[44,45]$ are utilized to design adaptive controller for nonlinear system with parameters uncertainty and external disturbances; the robustness and anti-interference ability of control system are improved.

The static var compensator (SVC) control is also one of the effective and economical means of improving the stability of power systems. Generally, the generator excitation controller and the SVC controller are designed independently of each other, but the uncoordinated control of the SVC and the excitation will have a negative effect and even lead to system instability. The research on the excitation control problem of SMIB power system with SVC has achieved remarkable results. In [46], the sliding mode dynamic surface method and disturbance attenuation technique are adopted. Considering the external disturbance and parameter uncertainty, a nonlinear adaptive robust coordination controller for SVC and generator excitation is designed. The energy-based coordinated stability controller is constructed by using the Hamiltonian function method in [47, 48], which effectively improves the transient stability and voltage regulation performance of the power systems. Immersion and invariant (I\&I) control method is widely used in the coordinated control of SVC and excitation. An I\&I adaptive control method is adopted to ensure that all single-machine infinitebus power system states are globally bounded and converge to a new stable equilibrium [3, 49]. However, in the actual operation of the power grid and power generation system, the system is more complicated and cannot be simply equivalent to a SMIB. Therefore, the excitation control of multimachine infinite-bus power systems with SVC has become the research emphasis of this paper.

Inspired by the above research works, the objective of this paper is to design a new adaptive controller for generators with SVC to ensure the stability of the system and the performance of the transient power system when the system has parameter uncertainties and actuator failures. The controller design process includes two partial steps. First, the dynamic surface is combined with the integral sliding mode to design the fault-tolerant controller of the generator excitation controller. Second, the SVC controller is designed. The main contributions of the proposed method are summarized as follows: (1) By introducing integral sliding mode surface in the dynamic surface control process, the problem of "differential explosion" in the traditional backstepping method is solved, and the structure of the controller is simplified. The introduction of the integral sliding mode surface makes the tracking error of the system converge to zero within a finite time, thereby ensuring the convergence speed and tracking accuracy of the closed-loop system, and the anti-interference ability of the system is also improved. (2) By introducing the actuator failure factor, an adaptive fault-tolerant controller is designed to solve the problem of actuator failure and ensure that the system can still be stable after partial actuator failure. (3) By adopting the minimum parameter learning method, the norm of ideal weight vector of radial basis function neural networks (RBFNNs) is estimated online, the "dimension disaster" problem caused by the traditional neural network due to the estimated weight vector is avoided, and the calculation burden of the controller is reduced.

The rest of this paper is organized as follows. In Section 2 , the mathematical model of the multimachine infinity-bus power systems with SVC is described. Coordination controller for generator excitation and SVC is designed in Section 3. The stability analysis is presented in Section 4 . The effectiveness of the proposed scheme is illustrated by simulation in Section 5. The conclusion is drawn in Section 6.

\section{System Dynamic Models and Problem Statement}

2.1. Mathematical Models. The dynamic model of multimachine infinite-bus power systems with SVC is given in this section, in which the dynamics of the $i$ th generator are described by a third-order differential equation, and the SVC is described by a first-order inertia equation. Then, the mathematical models of power system can be described as follows $[3,5]$ :

$$
\left\{\begin{array}{l}
\dot{\delta}_{i}(t)=\omega_{i}, \\
\dot{\omega}_{i}(t)=-\frac{D_{i}}{2 H_{i}} \omega_{i}+\frac{\omega_{i 0}}{2 H_{i}}\left(P_{m i}-P_{e i}\right), \\
\dot{E}_{q i}^{\prime}(t)=\frac{1}{T_{d 0 i}^{\prime}}\left[E_{f i}(t)-E_{q i}(t)\right],
\end{array}\right.
$$

with a SVC model 


$$
\dot{B}_{L i}=\frac{1}{T_{C i}}\left(-B_{L i}+B_{C i}+u_{B i}\right),
$$

and the electrical equations are as follows:

$$
\begin{aligned}
& E_{q i}(t)=E_{q i}^{\prime}(t)+\left(x_{d i}-x_{d i}^{\prime}\right) I_{d i}(t), \\
& E_{f i}(t)=k_{e i} u_{f i}(t), \\
& P_{e i}(t)=\sum_{j=1}^{n} E_{q i}^{\prime}(t) E_{q j}^{\prime}(t) B_{i j} \sin \left(\delta_{i}-\delta_{j}\right), \\
& Q_{e i}(t)=-\sum_{j=1}^{n} E_{q i}^{\prime}(t) E_{q j}^{\prime}(t) B_{i j} \cos \left(\delta_{i}-\delta_{j}\right), \\
& I_{d i}(t)=-\sum_{j=1}^{n} E_{q j}^{\prime}(t) B_{i j} \cos \left(\delta_{i}-\delta_{j}\right), \\
& I_{q i}(t)=\sum_{j=1}^{n} E_{q j}^{\prime}(t) B_{i j} \sin \left(\delta_{i}-\delta_{j}\right),
\end{aligned}
$$

where the explanation of symbols used in the dynamic model (1)-(8) is given in Table 1.

Remark 1. Generally, in order to accurately describe a largescale multimachine power system, a high-order complex nonlinear dynamic equation is required [28], which makes it very difficult to analyze the stability of the power system and design the excitation controller $[3,5]$. In order to overcome such difficulties, a third-order power system model simplified by the integral manifold method is proposed in $[5,50]$. This model makes the control system design and stability analysis feasible; and it has been widely used in the design of excitation controllers for multimachine power system $[7,26,51-53]$. The third-order power system mode and the first-order static reactive power compensator model adopted in this paper are derived from $[3,5]$.

In order to reduce the complexity of the controller design process in Section 3, $E_{q i}^{\prime}(t)$ in the generator electrical dynamics is eliminated by differentiating $P_{e i}(t)$ in (5):

$$
\begin{aligned}
\dot{P}_{e i}(t) & =\frac{1}{T_{d 0 i}^{\prime}}\left[\left(E_{f i}(t)-\left(x_{d i}-x_{d i}^{\prime}\right) I_{d i}(t)\right) I_{d i}(t)-P_{e i}(t)\right] \\
& -Q_{e i}(t) \omega_{i}+\gamma_{i}(\delta, \omega) .
\end{aligned}
$$

Let $\Delta P_{\mathrm{ei}}=P_{\mathrm{ei}}-P_{\mathrm{mi}}$; we have

$$
\Delta \dot{P}_{e i}(t)=\dot{P}_{e i}(t)=-\frac{1}{T_{d 0 i}^{\prime}} \Delta P_{e i}(t)+\frac{1}{T_{d 0 i}^{\prime}} u_{i}+\gamma_{i}(\delta, \omega) .
$$

The multimachine power systems model can be transformed into the following mathematical model $[1,5]$ : where $d_{i 1}$ and $d_{i 2}$ are bounded uncertainties, including modeling errors, measurement errors, and external disturbances. $u_{i}$ is the control signal of the generator with

$$
u_{i}=E_{f i}(t) I_{q i}(t)-\left(x_{d i}-x_{d i}^{\prime}\right) I_{d i}(t) I_{q i}(t)-P_{m i}-T_{d 0 i}^{\prime} Q_{e i}(t) \omega_{i} .
$$

By considering the failure fault of the actuator at time $t_{f}$, the generator excitation voltage $E_{f i}(t)$ can be defined as

$$
E_{f i}(t)=k_{e i}\left(1-\beta_{i}\right) u_{f i},
$$

where $\beta_{i}$ is the failure factor. So

$$
\begin{aligned}
u_{i}^{\prime}= & E_{f i}(t) I_{q i}(t)-\left(x_{d i}-x_{d i}^{\prime}\right) I_{d i}(t) I_{q i}(t)-P_{m i}-T_{d 0 i}^{\prime} Q_{e i}(t) \omega_{i} \\
& -\beta_{i} E_{f i}(t) I_{q i}(t) .
\end{aligned}
$$

So the multimachine power systems model by considering the failure fault can be described as follows:

$$
\left\{\begin{array}{l}
\dot{\delta}_{i}(t)=\omega_{i}, \\
\dot{\omega}_{i}(t)=-\frac{D_{i}}{2 H_{i}} \omega_{i}+\frac{\omega_{i 0}}{2 H_{i}}\left(P_{m i}-P_{e i}\right)+d_{i 1}, \\
\Delta \dot{P}_{e i}(t)=-\frac{1}{T_{d 0 i}^{\prime}} \Delta P_{e i}(t)+\frac{1}{T_{d 0 i}^{\prime}} u_{i}+\gamma_{i}(\delta, \omega)+d_{i 2}+F_{i},
\end{array}\right.
$$


TABLE 1: The notation for multimachine power systems with SVC.

\begin{tabular}{lc}
\hline Symbol & Nomenclature \\
\hline$\delta_{i}$ & The power angle of the ith generator, in rad \\
$\omega_{i}$ & The relative speed of theithgenerator, in rad/s \\
$\omega_{i 0}$ & The synchronous machine speed, in rad/s \\
$D_{i}$ & The per unit damping constant \\
$H_{i}$ & The inertia constant, in s \\
$P_{m i}$ & The mechanical input power, in p.u. \\
$P_{e i}$ & The electrical power, in p.u. \\
$E_{q i}^{\prime}$ & The transient EMF in the quadrature axis, in p.u. \\
$E_{f i}^{\prime}$ & The equivalent EMF in the excitation coil, in p.u \\
$E_{q i}$ & The EMF in the quadrature axis, in p.u. \\
$x_{d i}^{\prime}$ & The direct axis reactance, in p.u. \\
$x_{d i}^{\prime}$ & The direct axis transient reactance, in p.u. \\
$I_{d i}$ & The direct axis current, in p.u \\
$k_{e i}$ & The gain of the excitation amplifier, in p.u. \\
$u_{f i}$ & The input of the SCR amplifier, in p.u. \\
$Q_{e i}$ & The reactive power, in p.u. \\
$I_{q i}$ & The quadrature axis current, in p.u. \\
$B_{L i}$ & The adjustable equivalent susceptance in SVC \\
$B_{C i}$ & The initial value of adjustable susceptance \\
$u_{B i}$ & The input of SVC, in p.u. \\
$T_{C i}$ & The time constant of adjusting system and SVC \\
$T_{d 0 i}$ & The direct axis transient short-circuit time constant, in s \\
$B_{i j}$ & Th row and $j$ th column element of nodal susceptance matrix at the internal nodes after eliminating all physical buses, in p.u. \\
\hline
\end{tabular}

where

$$
\begin{aligned}
F_{i}= & -\beta_{i} \frac{1}{T_{d 0 i}{ }^{\prime}} E_{f i} I_{q i}, \\
\gamma_{i}(\delta, \omega)= & \sum_{j=1}^{n} E_{q i}^{\prime}(t) \dot{E}_{q j}^{\prime}(t) B_{i j} \sin \left(\delta_{i}-\delta_{j}\right) \\
& -\sum_{j=1}^{n} E_{q i}^{\prime}(t) E_{q j}^{\prime}(t) B_{i j} \cos \left(\delta_{i}-\delta_{j}\right) \omega_{j} .
\end{aligned}
$$

Here, the bound of the interconnection term $\gamma_{i}(\delta, \omega)$ satisfies

$$
\left|\gamma_{i}(\delta, \omega)\right| \leq \sum_{j=1}^{n}\left(\gamma_{i 1 j}\left|\sin \delta_{j}\right|+\gamma_{i 2}\left|\omega_{j}\right|\right) \leq \sum_{j=1}^{n}\left(\gamma_{i 1 j}\left|\delta_{j}\right|+\gamma_{i 2}\left|\omega_{j}\right|\right),
$$

where

$$
\begin{aligned}
& \gamma_{i 1 j} \triangleq \begin{cases}\frac{4 p 1 i j}{\left|T_{d 0 j}^{\prime}\right|_{\text {min }}}\left|P_{e i}\right|_{\text {max }}, & \text { when } j \neq i, \\
\sum_{j=1, j \neq i}^{n} \frac{4 p 1 i j}{\left|T_{d 0 j}^{\prime}\right|_{\text {min }}}\left|P_{e i}\right|_{\max }, & \text { when } j=i,\end{cases} \\
& \gamma_{i 2} \triangleq p_{2 i j}\left|Q_{e i}\right|_{\text {max }},
\end{aligned}
$$

with $p_{1 i j}$ and $p_{2 i j}$ being the constants with values of either 1 or $0 . P_{e i}(t)$ and $Q_{e i}(t)$ are readily measurable variables. From (5)-(8), we can obtain that

$$
\begin{gathered}
P_{e i}=E_{q i}^{\prime} I_{q i}, \\
Q_{e i}=-E_{q i}^{\prime} I_{d i} .
\end{gathered}
$$

Define the following state variables for coordinate transformation:

$$
\left\{\begin{array}{l}
x_{i 1}=\delta_{i}-\delta_{i 0} \\
x_{i 2}=\omega_{i}-\omega_{i 0} \\
x_{i 3}=\Delta P_{e i}=P_{e i}-P_{m i} \\
x_{i 4}=V_{m i}-V_{\mathrm{refi}}
\end{array}\right.
$$

where $P_{m i}=P_{m i 0}$ is a constant and

$$
V_{m i}=\frac{\sqrt{\left(X_{2 i} E_{q i}^{\prime}\right)^{2}+\left(X_{1 i}\right)^{2}+2 X_{1 i} X_{2 i} E_{q i}^{\prime} \cos x_{i 1}}}{X_{d \sum_{i}^{\prime}}}
$$

where $V_{m i}$ is the accessing point voltage and $V_{\text {refi }}$ is the corresponding reference voltage of the SVC:

$$
\begin{aligned}
X_{1 i} & =x_{d i}^{\prime}+X_{T i}, \\
X_{d \sum_{i}^{\prime}} & =X_{1 i}+X_{2 i}+X_{1 i} X_{2 i}\left(B_{L i}-B_{C i}\right),
\end{aligned}
$$

where $X_{2 i}$ and $X_{T i}$ are the transmission line reactance and the transformer reactance, respectively. According to (2) and 
(15) and (20), we can obtain the following mathematical model of multimachine power systems with SVC:

$$
\begin{aligned}
& \left\{\begin{array}{l}
\dot{x}_{i 1}=x_{i 2} \\
\dot{x}_{i 2}=f_{i 2}\left(\bar{x}_{i 2}\right)-g_{i 2} x_{i 3}+d_{i 1}, \\
\dot{x}_{i 3}=f_{i 3}\left(\bar{x}_{i 3}\right)+g_{i 3} u_{i}+\gamma_{i}(\delta, \omega)+d_{i 2}+F_{i}, \\
y_{i 1}=x_{i 1},
\end{array}\right. \\
& \left\{\begin{array}{l}
\dot{x}_{i 4}=g_{i 4} u_{B i}^{\prime}+f_{i 4}\left(\bar{x}_{i 4}\right), \\
y_{i 2}=x_{i 4},
\end{array}\right.
\end{aligned}
$$

where $y_{i 1}$ is the output of multimachine power systems, $y_{i 2}$ is the output of the SVC, and

$$
\begin{aligned}
& f_{i 2}\left(\bar{x}_{i 2}\right)=-\frac{D_{i}}{2 H_{i}} x_{i 2}, \\
& f_{i 3}\left(\bar{x}_{i 3}\right)=-\frac{1}{T_{d 0 i}^{\prime}} x_{i 3} \text {, } \\
& f_{i 4}\left(\bar{x}_{i 4}\right)=-\frac{\sin x_{i 1} X_{1 i} X_{2 i}}{\left(x_{i 4}+V_{\text {refi }}\right)\left(X_{d \sum_{i}^{\prime}}\right)^{2}} x_{i 2} E_{q i}^{\prime} \\
& -\frac{X_{1 i} X_{2 i}\left(x_{i 4}+V_{\mathrm{refi}}\right)}{X_{d \sum^{\prime}{ }^{\prime} T_{C i}}}\left(-B_{L i}+B_{C i}\right) \\
& +\frac{X_{2 i}^{2} E_{q i}^{\prime}+X_{1 i} X_{2 i} \cos x_{i 1}}{\left(x_{i 4}+V_{r e f i}\right)\left(X_{d \sum_{i}^{\prime}}\right)^{2}} \\
& \cdot\left(-\frac{X_{d \sum_{i}}}{T_{d 0 i} X_{d \sum^{\prime}}^{\prime}} E_{q i}^{\prime}+\frac{1}{T_{d 0 i}} \frac{X_{d i}-X_{d i}^{\prime}}{X_{d \sum_{i}^{\prime}}} \cos x_{i 1}\right) \\
& +\frac{X_{2 i}^{2} x_{i 3}+X_{1 i} X_{2 i} V_{s i} \cos \delta_{i}}{T_{d 0 i} V_{m i}\left(X_{d} \sum_{i}^{\prime}\right)^{2}} u_{i} \\
& g_{i 2}=\frac{\omega_{i 0}}{2 H_{i}}, \\
& g_{i 3}=\frac{1}{T_{d 0 i}^{\prime}}, \\
& g_{i 4}=\frac{X_{1 i} X_{2 i}}{T_{C i} X_{d} \sum_{i}^{\prime}} \\
& u_{B i}^{\prime}=-x_{i 4} u_{B i} \text {, }
\end{aligned}
$$

with

$$
\begin{aligned}
X_{d \sum_{i}} & =X_{3 i}+X_{2 i}+X_{3 i} X_{2 i}\left(B_{L i}-B_{C i}\right), \\
X_{3 i} & =x_{d i}+X_{T i} .
\end{aligned}
$$

Since the damping coefficient $D_{i}$ is difficult to measure accurately, $D_{i}$ is treated as an uncertainty parameter, and the nonlinear system with uncertain parameters (1) is transformed by equation (20) into a feedback form as shown in equation (23), so that the dynamic surface integral sliding mode method can be used to design the controller of the system equation (23). We can make the following two assumptions in this paper.

Assumption 1. The signs of $g_{i j}, i=1,2, j=2,3,4$, are unknown bounded positive parameters, and there are known positive constants $g_{\max }$ and $g_{\min }$ such that $g_{\max } \geq g_{i j} \geq g_{\min }$; $f_{i 2}\left(\bar{x}_{i 2}\right), f_{i 3}\left(\bar{x}_{i 3}\right)$, and $f_{i 4}\left(\bar{x}_{i 4}\right)$ are unknown continuous functions.

Assumption 2. The reference signal $x_{i 1 d}$ is bounded and smooth function, its first and second derivatives both exist, and there is a positive real number $B_{i 0}$ that satisfies $x_{i 1 d}^{2}+\dot{x}_{i 1 d}^{2}+\ddot{x}_{i 1 d}^{2} \leq B_{i 0}$.

Remark 2. Since $g_{i j}, i=1,2, j=2,3,4$, are unknown bounded positive parameters and the reference signal $x_{i 1 d}$ is a bounded smoothing function, Assumptions 1 and 2 are reasonable and common assumptions in $[24,26]$.

2.2. Radial Basis Function Neural Networks (RBFNNs). The unknown nonlinear continuous functions are approximated by the RBFNNs in this study. The general form of RBFNNs can be expressed as

$$
y(\xi)=W^{T} \mathcal{E}(\xi)
$$

where $\xi \in R^{n}$ is the input of RBFNNs, $y(\xi) \in R$ is the output of RBFNNs, $W \in R^{N}$ is the adjustable weight vector, and $\varepsilon(\xi) \in R^{N}$ is the nonlinear vector function.

In general, a continuous nonlinear function $F: \Omega_{\xi} \longrightarrow R$ with $\Omega_{\xi} \in R^{n}$ being a compact set and an approximation error $\sigma_{m}>0$ are given such that $\left|F(\xi)-W^{* T} \mathcal{E}(\xi)\right| \leq \sigma_{m}, \forall \xi \in \Omega_{\xi}$. Therefore, $F(\xi)$ can be described as $F(\xi)=W^{*^{T}} \varepsilon(\xi)+\sigma^{*}, \forall \xi \in \Omega_{\xi} \in R^{n}$, where $\sigma^{*}$ is the approximation error and satisfies $\left|\sigma^{*}\right| \leq \sigma_{m}$. The optimal weight vector $W^{*}$ for analytical purposes can be defined as

$$
W^{*}=\arg \min _{W \in R^{N}}\left\{\sup _{\xi \in \Omega_{\xi}}\left|F(\xi)-W^{T} \mathcal{E}(\xi)\right| \leq \sigma_{m}\right\} .
$$

\section{Process of the Controller Design}

The design process of the controller is divided into two parts: the design of control law for multimachine excitation systems and the design of control law for SVC. The detailed design procedure is described in the following steps. Step 1 and 2 apply the dynamic surface method, and Step 3 uses integral sliding mode control. According to (24), we know that the model of SVC is of the first order. Therefore, the dynamic surface control method is used to design the controller of SVC in Step 4. The design scheme of the adaptive dynamic surface integral sliding mode fault-tolerant controller is shown in Figure 1, and the design steps are displayed in Table 2. 


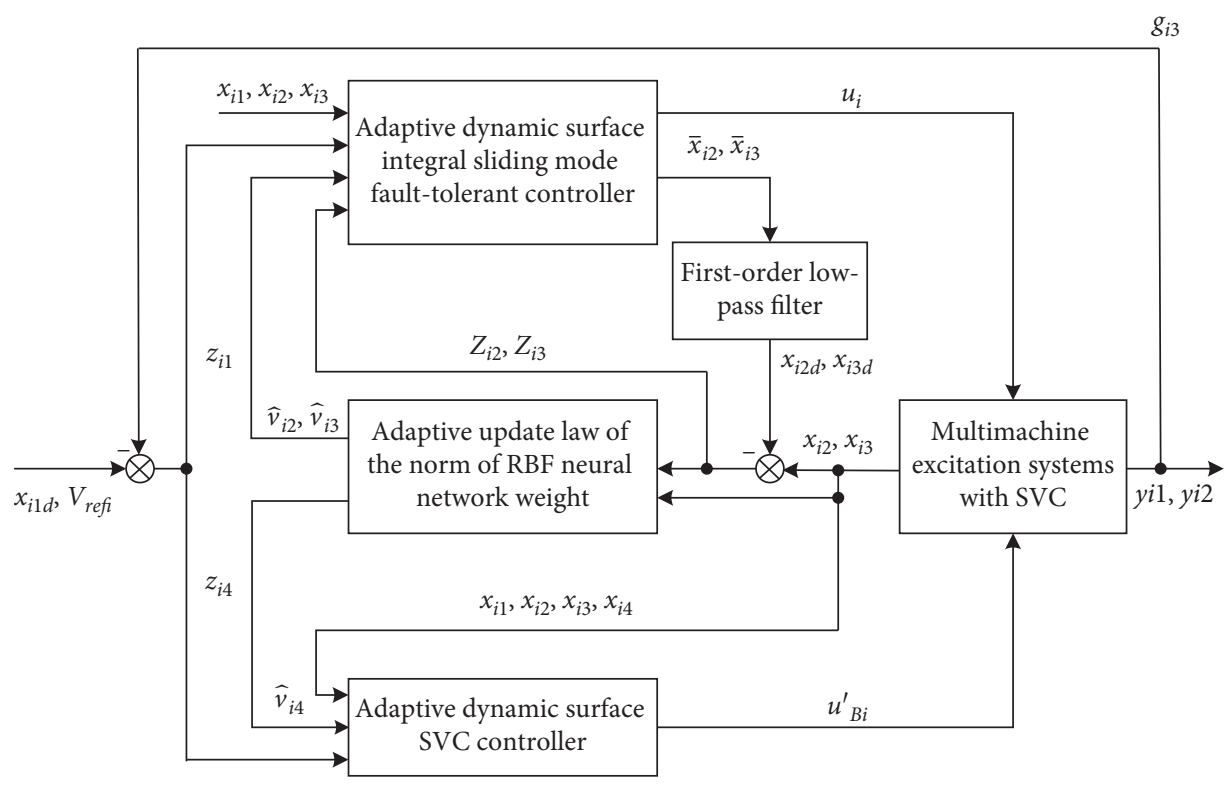

FIGURE 1: Schematic diagram of the proposed control scheme.

TABle 2: Adaptive dynamic surface integral sliding mode faulttolerant control.

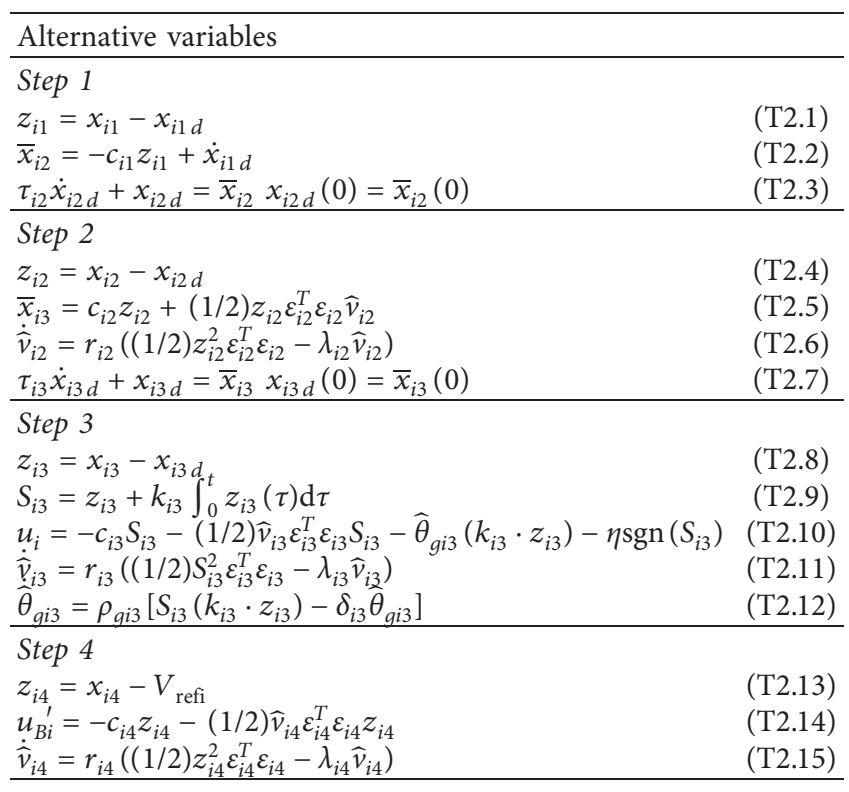

In Table $2, z_{i j}(j=1,2,3,4)$ are the $j$ th surface errors with $x_{i 1 d}$ being the desired power angle of the $i$ th generator. $S_{i 3}$ represents the designed integral sliding mode surface. $\bar{x}_{i 2}$ and $\bar{x}_{i 3}$ are the virtual control laws in Step 1 and Step 2. (T2.3) and (T2.7) are first-order low-pass filters, which are used to overcome the differential explosion problem in backstepping method. $\tau_{i 2}$ and $\tau_{i 3}$ are the time constants of (T2.3) and (T2.7). $\widehat{v}_{i 2}, \widehat{v}_{i 3}, \widehat{v}_{i 4}$, and $\widehat{\theta}_{g i 3}$ are adaptive laws. $u_{i}$ and $u_{B i}^{\prime}$ are the actual control laws of generator excitation and SVC, respectively. $c_{i j}(j=1,2,3,4), r_{i l}, \lambda_{i l}(l=2,3,4) \rho_{\text {gi3 }}$, $\delta_{i 3}$, and $k_{i 3}$ are positive design parameters. $\widetilde{v}_{i l}=\widehat{v}_{i l}-v_{i l}^{*}(l=$ $2,3,4)$ and $\widehat{v}_{i l}(l=2,3,4)$ are the estimation of $v_{i l}^{*}=\left\|W_{i l}^{*}\right\|^{2}$ with $W_{i l}^{*}$ being the optimal weight vector of the RBF neural networks in (A.9), (A.17), and (A.23). $\widetilde{\theta}_{g i 3}=\widehat{\theta}_{\text {gi3 }}-\theta_{\text {gi3 }}^{*}$ with $\widehat{\theta}_{\text {gi3 }}$ being the estimation of $\theta_{\text {gi3 }}^{*}=\left(1 / g_{i 3}\right)$.

Remark 3. A neural network based adaptive robust controller is developed by using the traditional backstepping design method in $[2,54]$. Although the semiglobal ultimate uniform boundedness of all signals in the control system is achieved, there is a problem of "explosion of complexity." In this paper, the introduction of a first-order low-pass filter overcomes the problem.

Remark 4. The values of time constants $\tau_{i 2}$ and $\tau_{i 3}$ should be chosen to be as small as possible. According to the actual condition, their values are usually between 0.001 and 0.1 .

Remark 5. In order to achieve better transient performance while maintaining the tracking accuracy of the control, the integral sliding mode surface $S_{i 3}$ is adopted in Step 3, which greatly improves the robustness of the system.

Remark 6. The saturation function sat $(\cdot)$ is used instead of the symbol function $\operatorname{sgn}(\cdot)$ to attenuate the chattering phenomenon of sliding mode control. The expressions of the sat $(\cdot)$ function can be written as $\operatorname{sat}\left(S_{i 3}\right)=\operatorname{sign}\left(S_{i 3}\right)$ (if $\left.\left|S_{i 3}\right|>\varphi\right)$,sat $\left(S_{i 3}\right)=S_{i 3} / \varphi\left(\right.$ if $\left.\left|S_{i 3}\right| \leq \varphi\right)$, where $\varphi>0$.

Remark 7. The adaptive fault-tolerant controller proposed in this paper is based on the dynamic surface control (DSC) technique [25]. Subsystems (23) and (24) are third-order system and first-order system, respectively. Therefore, the controller design process consists of 4 steps, and the actual control input signals (T2.10) and (T2.14) are obtained in the $3 \mathrm{rd}$ and 4th steps. In addition, the detailed information of the DSC method is described in some literatures, such as $[13,15,24]$. In order to make the article more concise, the 
specific design process of DSC is omitted, and only the necessary intermediate variables are given in Table 2 .

\section{Stability Analysis}

The stability analysis of the multimachine power systems with SVC will be given in this section. First of all, define the filter errors $y_{i 2 e}$ and $y_{i 3 e}$ :

$$
\begin{aligned}
& y_{i 2 e}=x_{i 2 d}-\bar{x}_{i 2}=x_{i 2 d}-\left(-c_{i 1} z_{i 1}+\dot{x}_{i 1 d}\right), \\
& y_{i 3 e}=x_{i 3 d}-\bar{x}_{i 3}=x_{i 3 d}-\left(c_{i 2} z_{i 2}+\frac{z_{i 2} \widehat{v}_{i 2} \varepsilon_{i 2}^{T} \varepsilon_{i 2}}{2}\right) .
\end{aligned}
$$

From (T2.3) and (29), we have

$$
\dot{x}_{i 2 d}=\frac{\bar{x}_{i 2}-x_{i 2 d}}{\tau_{i 2}}=-\frac{y_{i 2 e}}{\tau_{i 2}} .
$$

Similarly, from (T2.7) and (30), we have

$$
\dot{x}_{i 3 d}=\frac{\bar{x}_{i 3}-x_{i 3 d}}{\tau_{i 3}}=-\frac{y_{i 3 e}}{\tau_{i 3}} .
$$
and

There are nonnegative continuous functions $B_{i 2}$ and $B_{i 3}$,

$$
\begin{aligned}
& \left|\dot{y}_{i 2 e}+\frac{y_{i 2 e}}{\tau_{i 2}}\right| \leq B_{i 2}\left(z_{i 1}, z_{i 2}, y_{i 2 e}, x_{i 1 d}, \dot{x}_{i 1 d}, \ddot{x}_{i 1 d}\right), \\
& \left|\dot{y}_{i 3 e}+\frac{y_{i 3 e}}{\tau_{i 3}}\right| \leq B_{i 3}\left(z_{i 1}, z_{i 2}, z_{i 3}, y_{i 2 e}, y_{i 3 e}, \widehat{v}_{i 2}, x_{i 1 d}, \dot{x}_{i 1 d}, \ddot{x}_{i 1 d}\right),
\end{aligned}
$$

where

$$
\begin{aligned}
& B_{i 2}=c_{i 1} \dot{z}_{i 1}-\ddot{x}_{i 1 d}=c_{i 1}\left(z_{i 2}+y_{i 2 e}-c_{i 1} z_{i 1}\right)-\ddot{x}_{i 1 d} \\
& B_{i 3}=-\left[c_{i 2} \dot{z}_{i 2}+\frac{\dot{z}_{i 2} \widehat{v}_{i 2} \varepsilon_{i 2}^{T} \varepsilon_{i 2}}{2}+\frac{z_{i 2} \dot{\hat{v}}_{i 2} \varepsilon_{i 2}^{T} \varepsilon_{i 2}}{2}+\widehat{v}_{i 2} \varepsilon_{i 2}^{T} \varepsilon_{i 2}\left(\sum_{l=1}^{2} \frac{\partial \varepsilon_{i 2}}{\partial x_{i l}} \dot{x}_{i l}+\frac{\partial \varepsilon_{i 2}}{\partial z_{i 2}} \dot{z}_{i 2}\right)\right] .
\end{aligned}
$$

Consider the following Lyapunov function condition:

$$
V=\sum_{k=1}^{4} V_{i k}+\sum_{i=1}^{n} \frac{1}{2} y_{i 2 e}^{2}+\sum_{i=1}^{n} \frac{1}{2} y_{i 3 e}^{2} .
$$

Theorem 1. Consider the closed-loop control system, including multimachine systems model with actuator failure (23), SVC system model (24), first-order low-pass filters (T2.3) and (T2.7), actual control laws (T2.10) and (T2.14), and adaptive update laws (T2.6), (T2.11), (T2.12), and (T2.15). If Assumptions 1 and 2 are satisfied and the initial condition satisfies $V(0) \leq p$, where $p$ is arbitrary positive constant, then all closed-loop signals such as $z_{i 1}, z_{i 2}, z_{i 3}, z_{i 4}, v_{i 2}, v_{i 3}, v_{i 4}, \theta_{\text {gi3 }}$ are semiglobally uniformly bounded and the tracking error can converge to an arbitrarily small range by adjusting $p a-$ rameters $c_{i 1}, c_{i 2}, c_{i 3}, c_{i 4}, \lambda_{i 2}, \lambda_{i 3}, \lambda_{i 4}, \delta_{i 3}, k_{i 3}, \tau_{i 2}, \tau_{i 3}, i=1,2$. In addition, the integral sliding mode surface shown in (T2.9) can eliminate the steady-state error of the system tracking and ensure the robustness of the system.

Proof. The specific proof can be seen in the Appendix.

\section{Simulation Result and Analysis}

Simulation studies are meticulously discussed in this section. In order to verify the control performance of the dynamic surface integral sliding mode coordination controller designed in this paper, the dynamic simulation of the 2machine power system with SVC shown in Figure 2 is performed, where XT1 and XT2 represent the transformers and $2 X_{L 1}$ and $2 X_{L 2}$ represent the transmission lines. Some simulation parameters are selected as in [26].

The design parameters of the control laws including the virtual control laws and the final control laws are selected as $c_{11}$ $=8, c_{21}=8, c_{12}=3, c_{22}=3, c_{13}=60, c_{23}=60, c_{14}=20, c_{24}=$ 20. The updated laws are chosen as $\lambda_{12}=\lambda_{22}=0.3, r_{12}=r_{22}=$ $2, \lambda_{13}=\lambda_{23}=0.3, r_{13}=r_{23}=2, \rho_{g 13}=\rho_{g 23}=0.6, \delta_{13}=\delta_{23}=$ $1, \lambda_{14}=\lambda_{24}=0.5$, and $r_{14}=r_{24}=1$.

The parameters of the integral sliding mode control are selected as $k_{13}=k_{23}=0.5$. The time parameters of the lowpass filter are chosen as $\tau_{12}=\tau_{22}=0.005$ and $\tau_{13}=\tau_{23}=0.005$. In addition, the interference signals are selected as $d_{i 1}=0.001 \cos (2 t)$ and $d_{i 2}=0.001 \sin (t) \cos (2 t)$.

In order to verify the effectiveness of the designed controller, the tracking performances of the following four controllers are compared in Figures 3-5 under three conditions. (1) Two generators adopt the excitation controller with SVC designed by the traditional adaptive backstepping control (TABSC) method. (2) Two generators adopt the coordinated controller designed by the adaptive dynamic surface control (DSC) method. (3) Two generators adopt the coordinated controller designed by the adaptive sliding mode control (SMC) method. (4) The two generators adopt the coordination controller designed by dynamic surface integral sliding mode control (DSISMC) method in this paper. 


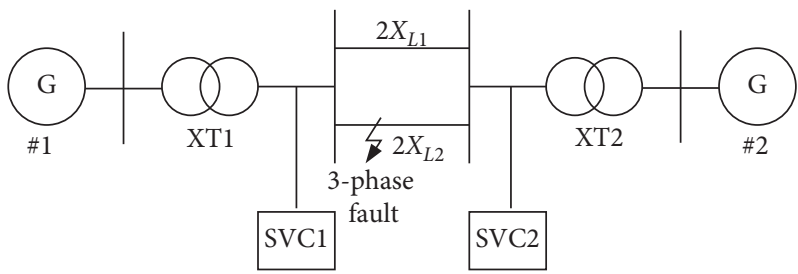

FIGURE 2: The structure of 2-machine power system with SVC.
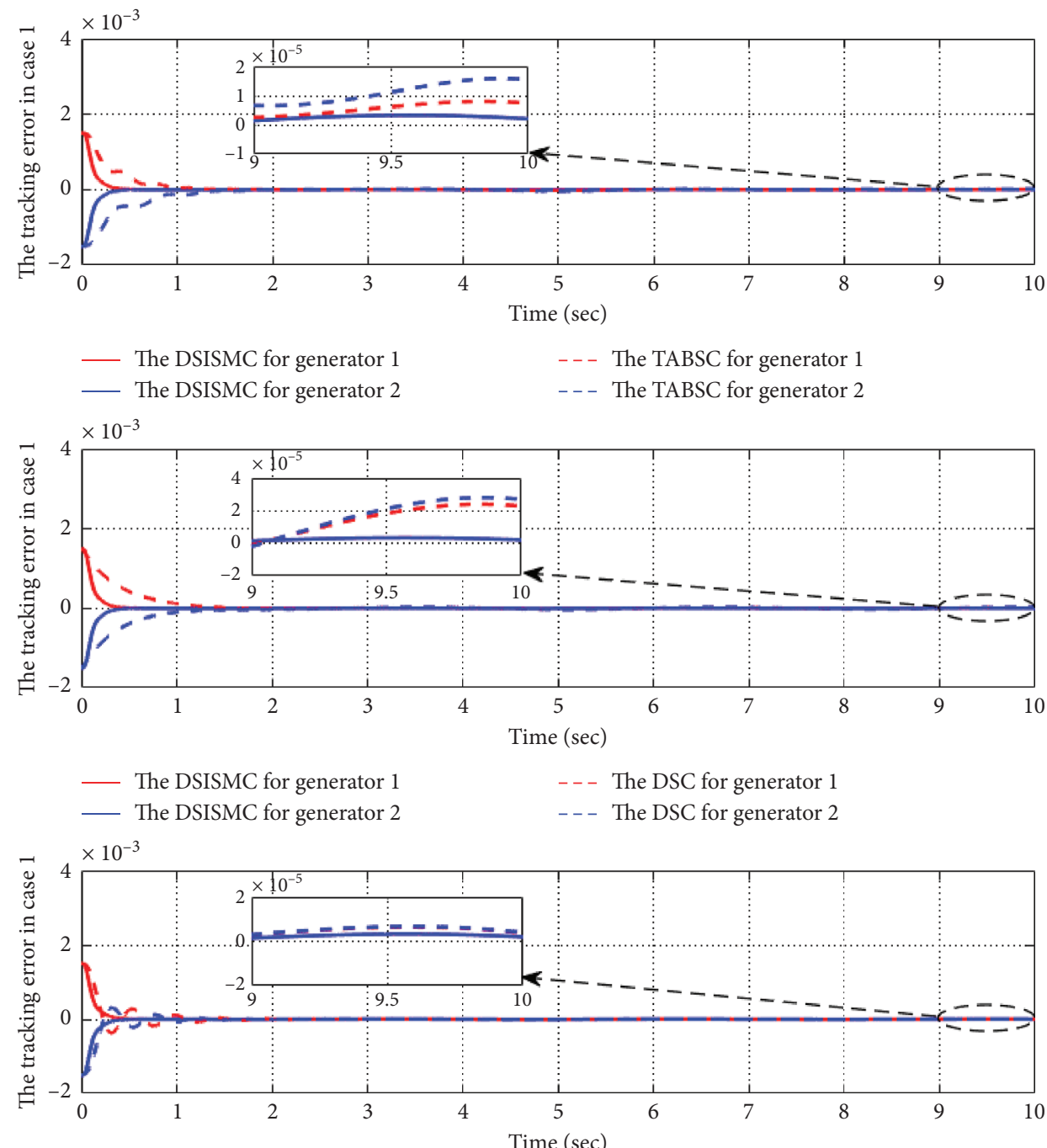

The DSISMC for generator 1

- - - The SMC for generator 1

- The DSISMC for generator 2

- - - The SMC for generator 2

Figure 3: The tracking error of power angles $\delta_{i}, i=1,2$ by using four controllers for the two generators in Case 1. 

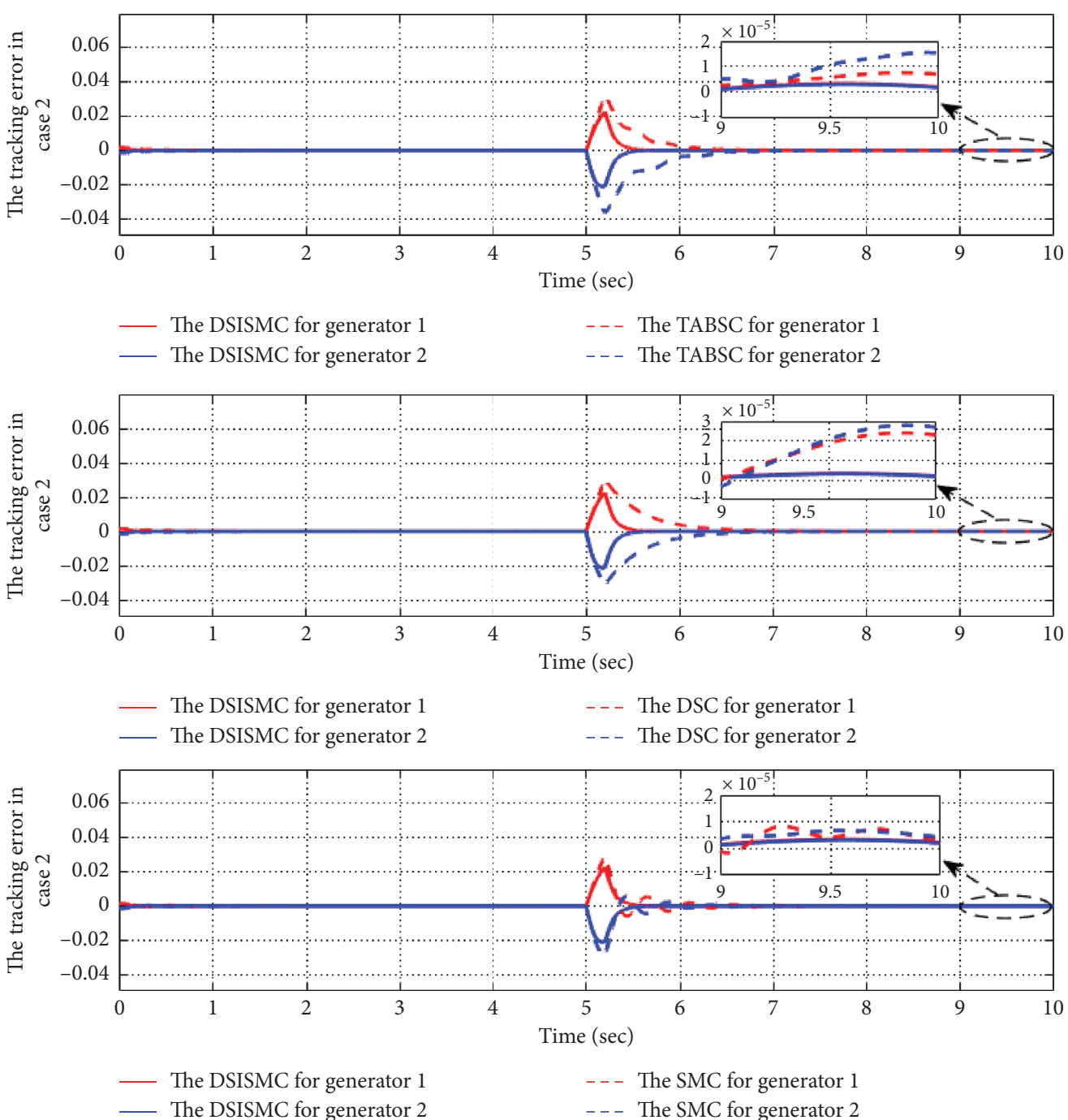

Figure 4: The tracking error of power angles $\delta_{i}, i=1,2$, by using four controllers for the two generators in Case 2 .

Case 1. The operating points are selected as follows:

$$
\begin{aligned}
\delta_{10} & =40.415^{\circ}, \\
\omega_{10} & =314.06 \mathrm{rad} / \mathrm{s}, \\
P_{m 10} & =1.02 \text { p.u. }, \\
V_{\text {ref1 }} & =1.15 \text { p.u. } \\
\delta_{20} & =40.285^{\circ}, \\
\omega_{20} & =313.94 \mathrm{rad} / \mathrm{s}, \\
P_{\text {m20 }} & =0.98 \text { p.u. } \\
V_{\text {ref2 }} & =1.05 \text { p.u.. }
\end{aligned}
$$

Figures 3 and 6-11 show the simulation results in Case 1. Figure 3 shows the tracking error of power angle $\delta_{i}$ under four controllers; it can be seen that, compared to the controllers designed by the other three methods, the dynamic surface integral sliding mode method adopted in this paper has better dynamic performance in terms of overshoot and stable operation time. The time required to achieve stabilization is shortened by $1 \sim 2 \mathrm{~s}$, and the fluctuation range is also significantly improved. According to Figure 3, the steady state (9 10) can be selected to obtain the maximum value of tracking error (MVTE) and the root mean square value of tracking error (RMSVTE) for the four control schemes as shown in Table 3. Figures 6-11 show the power angles $\delta_{1}, \delta_{2}$, the rotated speeds $\omega_{1}, \omega_{2}$, the electrical powers $P_{e 1}, P_{e 2}$, the control inputs $u_{1}, u_{2}$ of the excitation system, the accessing voltages $V_{m 1}, V_{m 2}$, and control inputs $u_{B 1}, u_{B 2}$ of SVC. It is proven by Figures 6-11 that the controller designed by combining dynamic surface and integral sliding mode has good control effect.

Case 2. The operating points are selected as follows:

$$
\begin{aligned}
\delta_{10} & =40.415^{\circ}, \\
\omega_{10} & =314.12 \mathrm{rad} / \mathrm{s}, \\
P_{m 10} & =1.01 \text { p.u. }, \\
V_{\text {ref } 1} & =1.15 \text { p.u., } \\
\delta_{20} & =40.285^{\circ}, \\
\omega_{20} & =314.16 \mathrm{rad} / \mathrm{s}, \\
P_{m 20} & =1.018 \text { p.u. } \\
V_{\text {ref2 }} & =1.05 \text { p.u.. }
\end{aligned}
$$




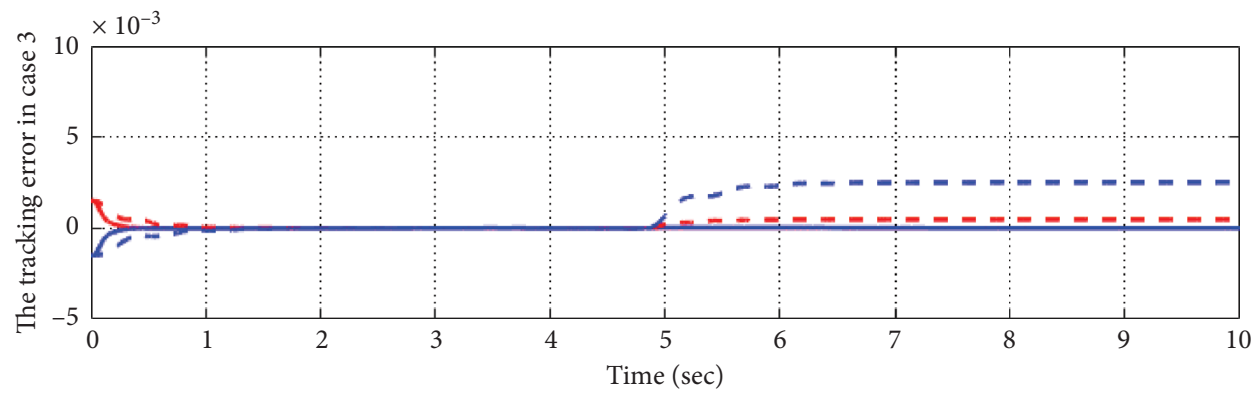

- The DSISMC for generator 1

- - - The TABSC for generator 1

The DSISMC for generator 2

- - - The TABSC for generator 2
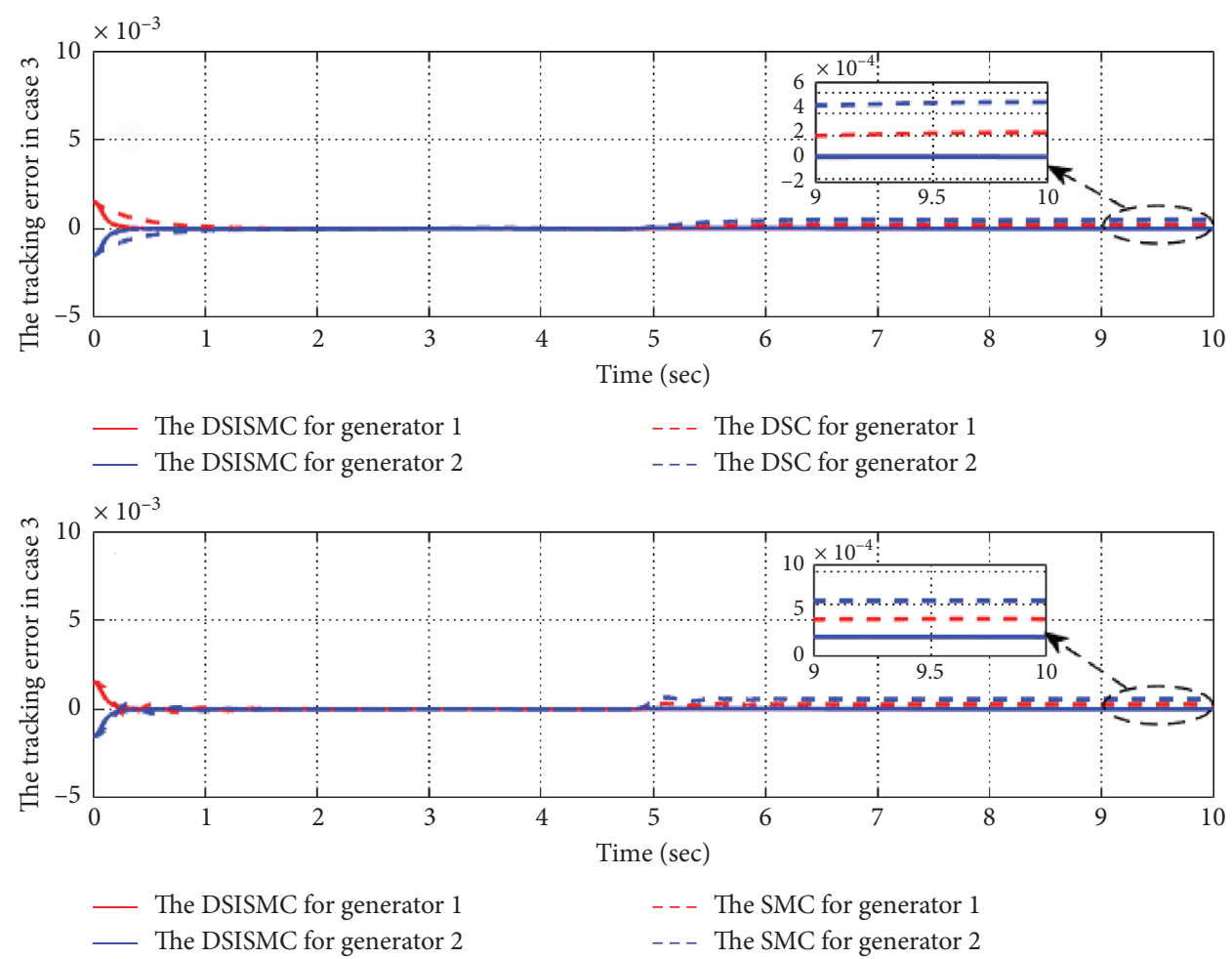

FIgURE 5: The tracking error of power angles $\delta_{i}, i=1,2$, by using four controllers for the two generators in Case 3.

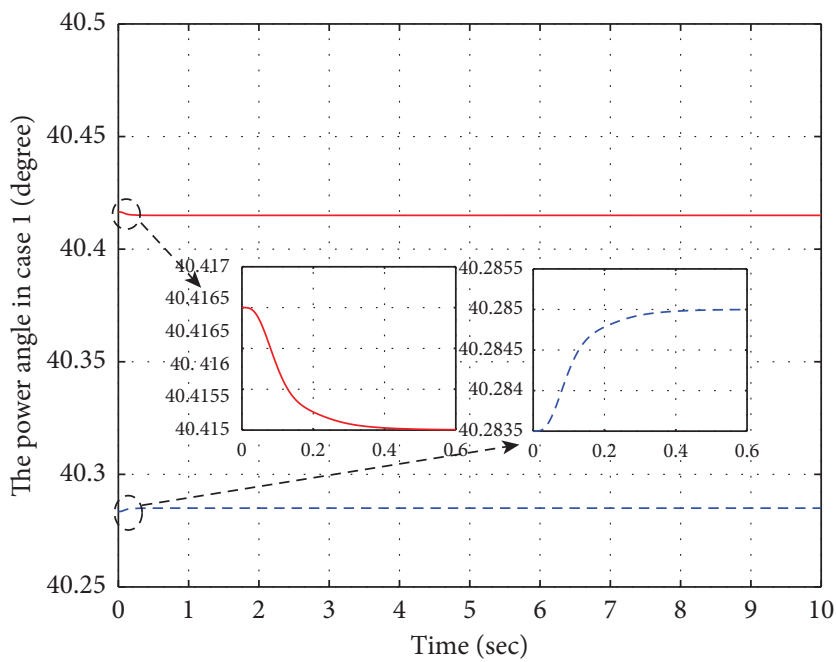

The power angle of generator 1

- - - The power angle of generator 2

Figure 6: The power angles $\delta_{i}, i=1,2$ of the two generators in Case 1 . 


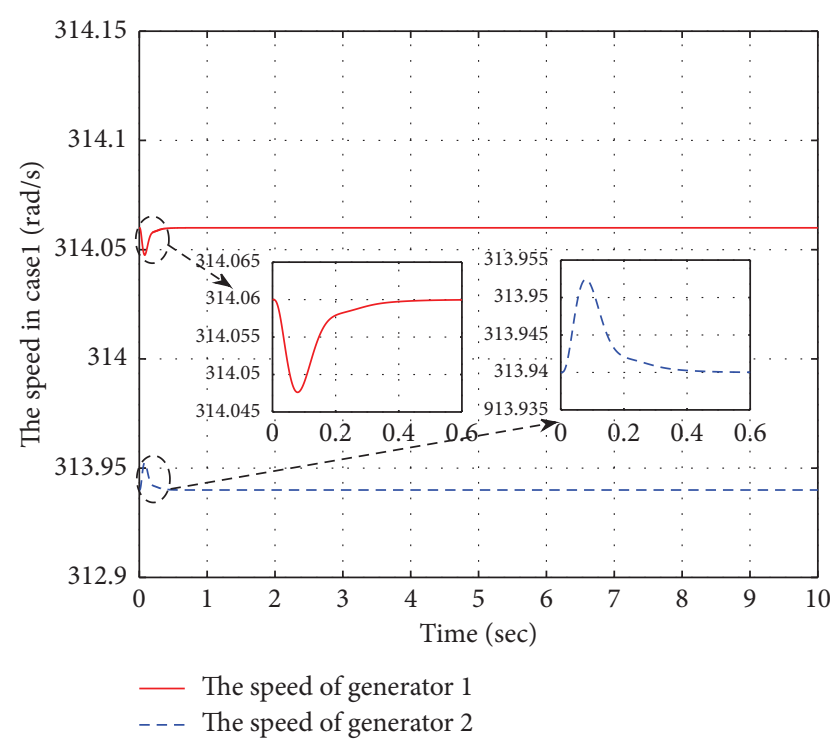

FIgURE 7: The rotated speed $\omega_{i}, i=1,2$ of the two generators in Case 1.

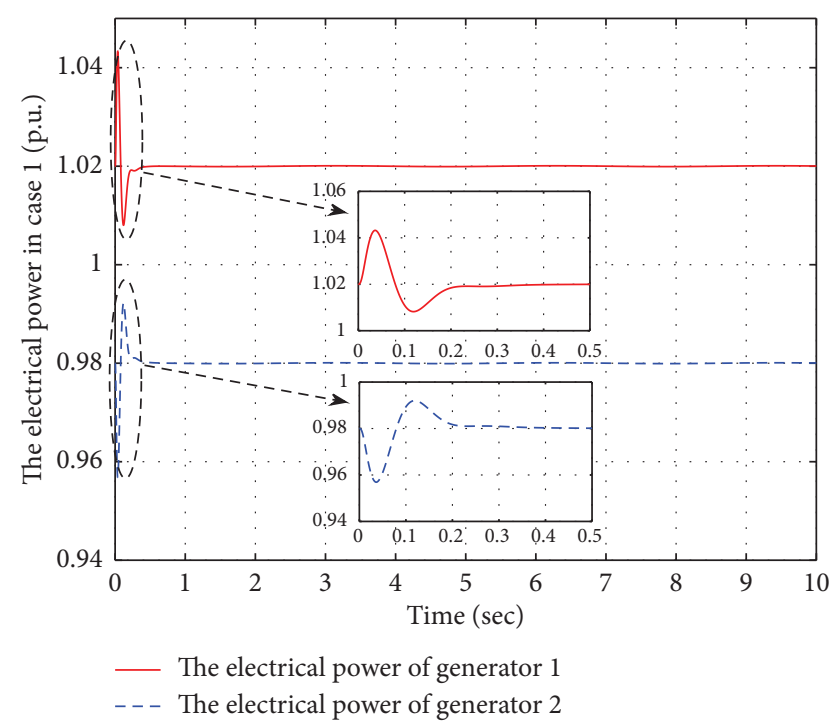

Figure 8: The electrical power $P_{e i}, i=1,2$ of the two generators in Case 1.

In the second case, it is assumed that the short circuit fault occurred on the transmission line at $t=5 \mathrm{~s}$ and disappeared after 0.2 seconds. Figures 4 and 12-17 show the simulation results in this case. Figure 4 shows the power angle tracking error $z_{i 1}, i=1,2$, of the four control schemes in the case of the short circuit; it can be seen that, after the short circuit fault disappears, the method adopted in this paper can make the tracking error quickly converge to the

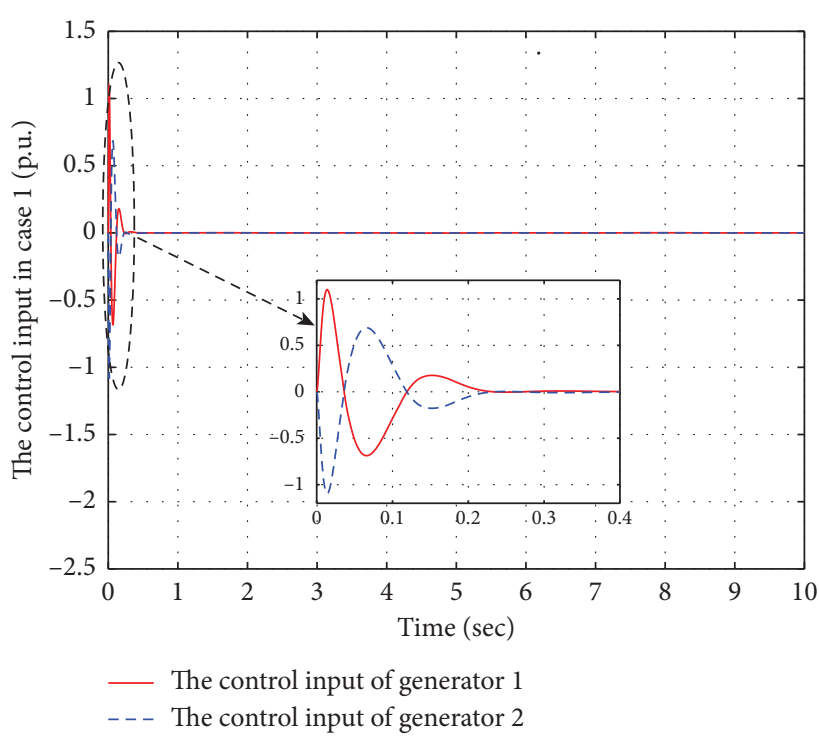

FIgURE 9: The control input $u_{i}, i=1,2$ of the two generators in Case 1.

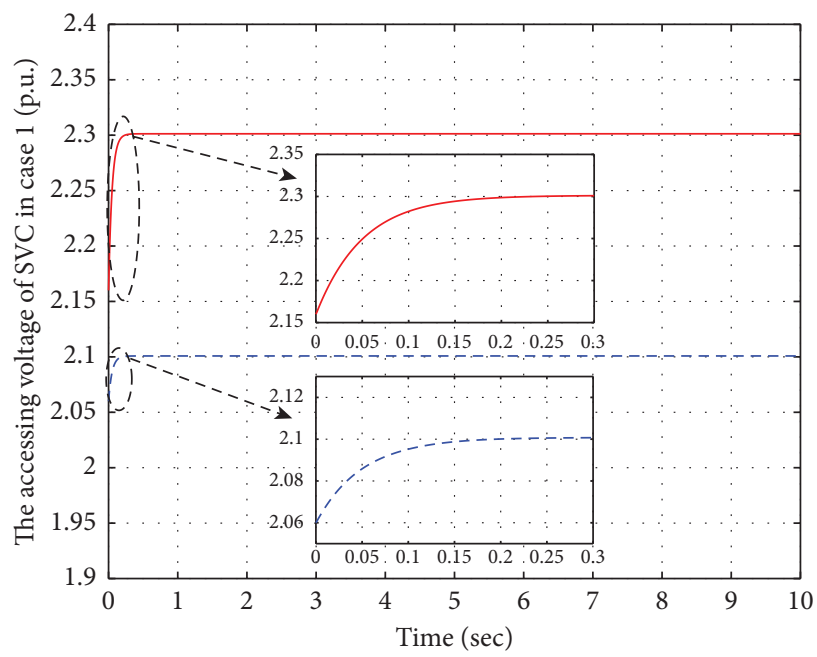

FIgURE 10: The accessing voltage $V_{\mathrm{mi}}, i=1,2$ of the SVC for the two generators in Case 1.

working point, so as to achieve the expected tracking performance of power angles. Similarly, according to Figure 4, the MVTE and RMSVTE in Case 2 can be given in Table 4. Figures 12-17 illustrate the curves of the power angles $\delta_{1}, \delta_{2}$, the rotated speeds $\omega_{1}, \omega_{2}$, the electrical powers $P_{e 1}, P_{e 2}$, the control inputs $u_{1}, u_{2}$ of the excitation system, the accessing voltages $V_{m 1}, V_{m 2}$, and the control inputs $u_{B 1}, u_{B 2}$ of SVC under the case that the unexpected short circuit fault occurred on the transmission line at $t=5 \mathrm{~s}$ and disappeared at $t=5.2 \mathrm{~s}$. 


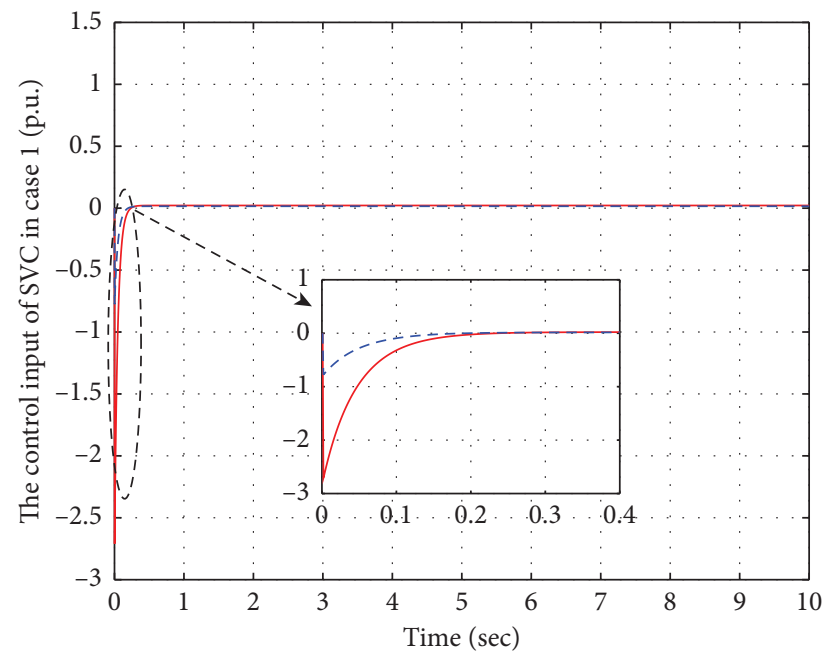

- The control input of SVC for generator 1

- - - The control input of SVC for generator 2

FIgURE 11: The control input $u_{B i}, i=1,2$ of the SVC in Case 1.

Table 3: The MVTE and RMSVTE in Case 1.

\begin{tabular}{|c|c|c|c|c|}
\hline Types of error & Proposed scheme & TBSC scheme & DSC scheme & SMC scheme \\
\hline MVTE of G\#1 & $3.3449 e^{-06}$ & $7.9840 e^{-06}$ & $2.3967 e^{-05}$ & $6.3628 e^{-06}$ \\
\hline MVTE of G\#2 & $3.3402 e^{-06}$ & $1.5855 e^{-05}$ & $2.8119 e^{-05}$ & $6.6305 e^{-06}$ \\
\hline RMSVTE of G\#1 & $2.8195 e^{-06}$ & $6.0995 e^{-06}$ & $1.7739 e^{-05}$ & $5.3544 e^{-06}$ \\
\hline RMSVTE of G\#2 & $2.8147 e^{-06}$ & $1.1737 e^{-05}$ & $2.0606 e^{-05}$ & $5.5828 e^{-06}$ \\
\hline
\end{tabular}

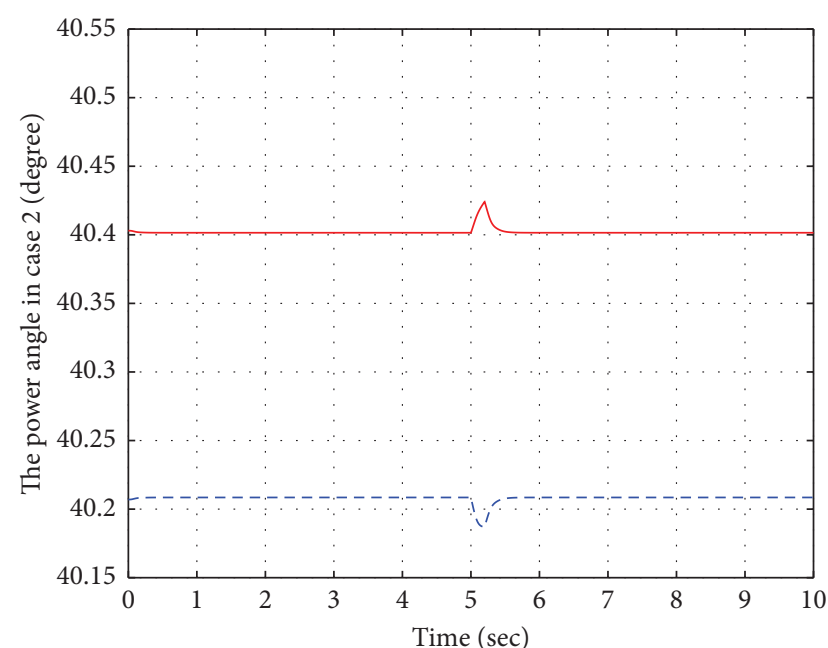

- The power angle of generator 1

- - - The power angle of generator 2

Figure 12: The power angles $\delta_{i}, i=1,2$, of the two generators in Case 2.

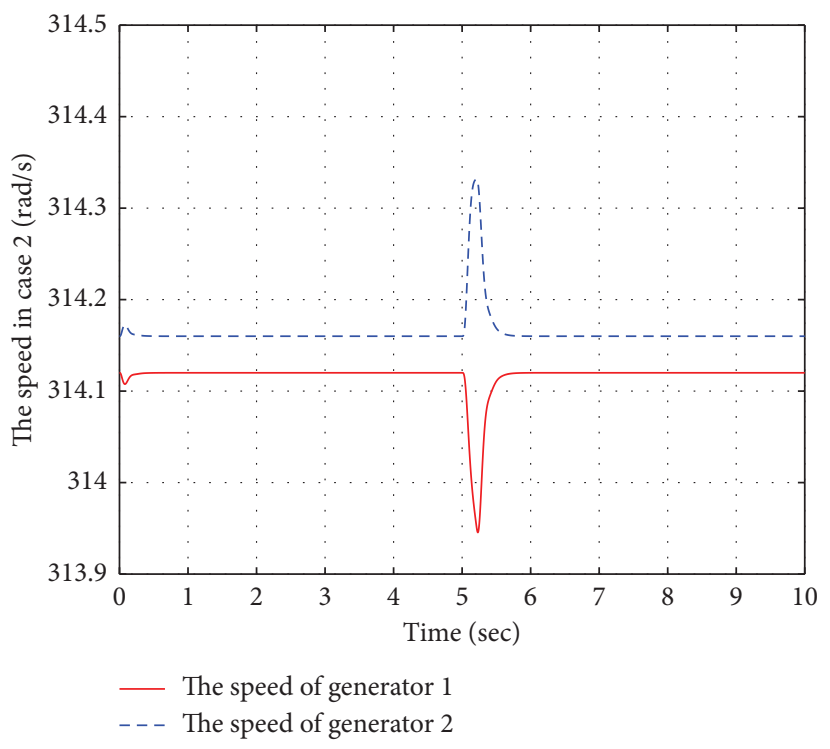

FIGURE 13: The rotated speeds $\omega_{i}, i=1,2$, of the two generators in Case 2. 


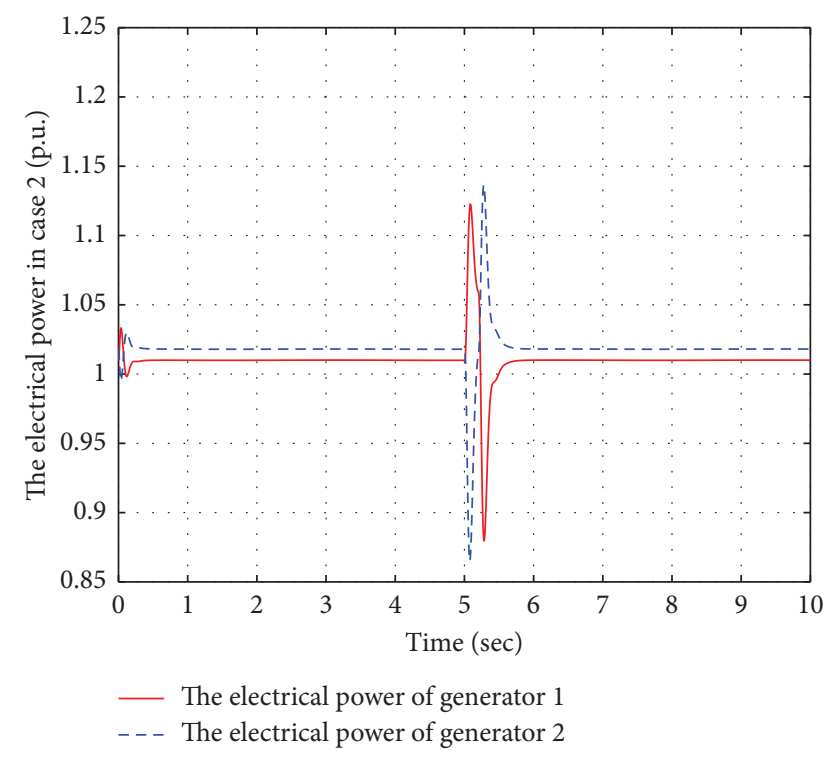

FIgUre 14: The electrical powers $P_{e i}, i=1,2$, of the two generators in Case 2.

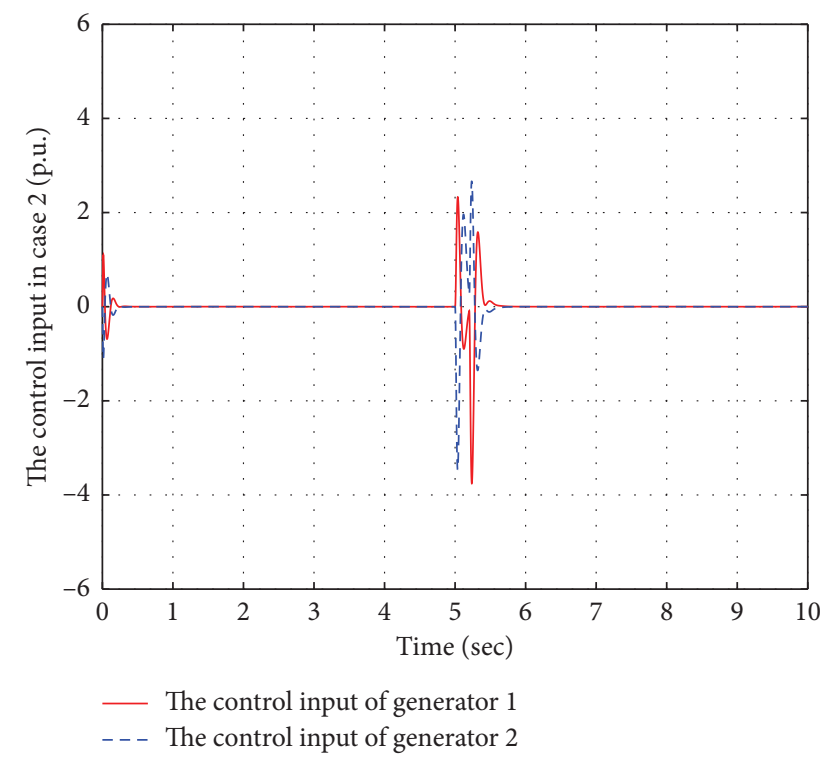

FIGURE 15: The control inputs $u_{i}, i=1,2$, of the two generators in Case 2.

Case 3. The operating points are selected as follows:

$$
\begin{aligned}
\delta_{10} & =40.4^{\circ}, \\
\omega_{10} & =314.10, \\
P_{m 10} & =1.02 \text { p.u., } \\
V_{\text {ref } 1} & =1.15 \text { p.u., } \\
\delta_{20} & =40.2^{\circ}, \\
\omega_{20} & =314.06 \mathrm{rad} / \mathrm{s}, \\
P_{m 20} & =1.00 \text { p.u., } \\
V_{\text {ref2 }} & =1.05 \text { p.u.. }
\end{aligned}
$$

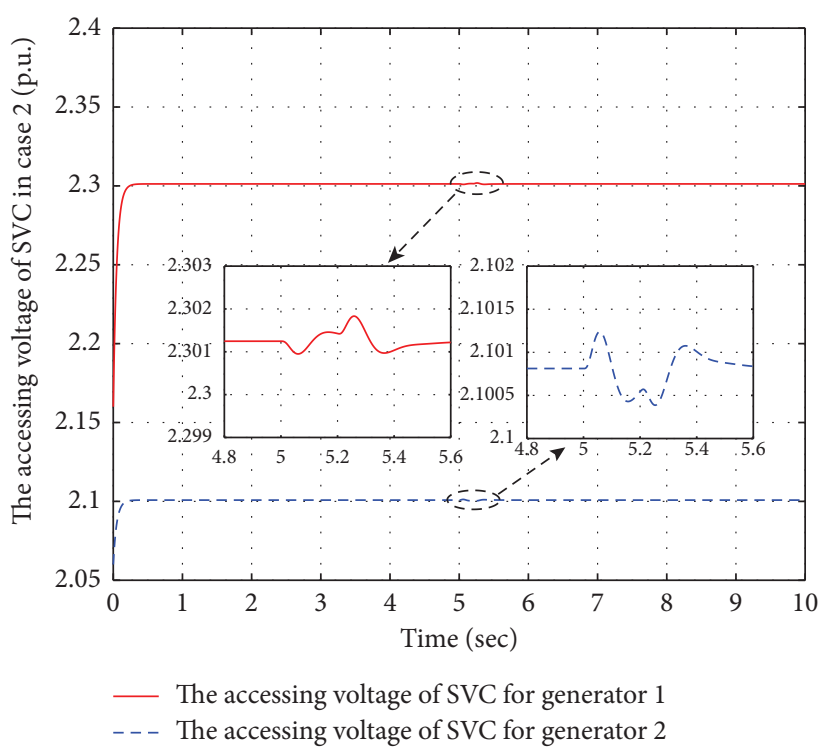

FIGURE 16: The accessing voltages $V_{m i}, i=1,2$, of the SVC for the two generators in Case 2.

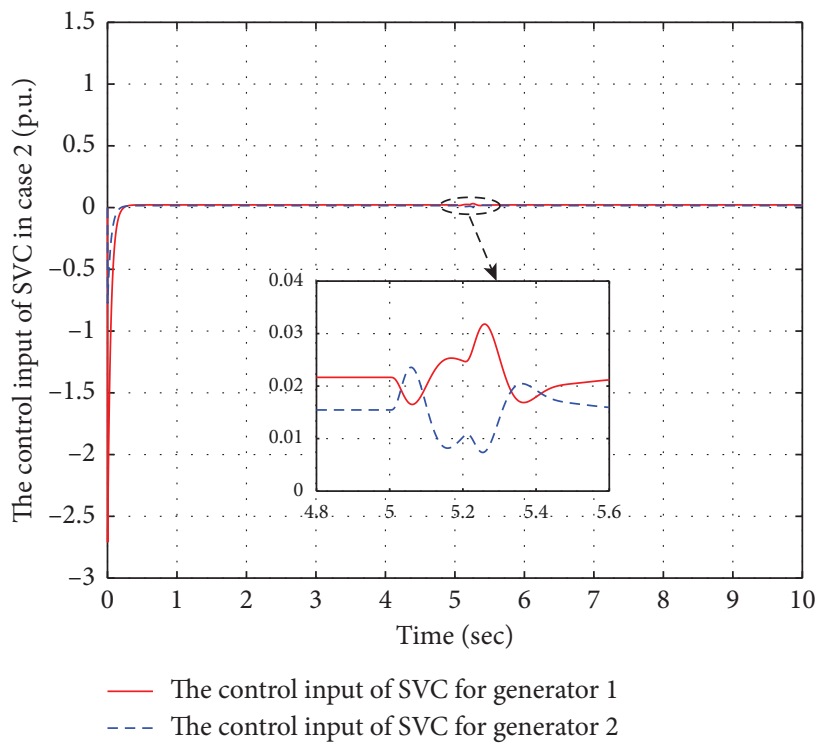

FIgURE 17: The control inputs $u_{B i}, i=1,2$, of the SVC in Case 2.

In this case, consider that an actuator failure fault occurs at time $t_{f}=4.8 \mathrm{~s}$, so $\bar{u}_{f i}$ can be assumed such that $\bar{u}_{f i}=\left(1-\beta_{i}\right) u_{f i}, t \geq t_{f}, \bar{u}_{f i}$ is the input of the SCR amplifier when failure occurs, and the multimachine excitation systems models with SVC in the case of failure fault are equations (23) and (24). The failure factors $\beta_{1}=0.2, \beta_{2}=0.4$. Figures 5 and $18-23$ show the simulation results in Case 3. Figure 5 illustrates the power angle tracking error $z_{i 1}, i=1,2$, of the four control schemes in the case of the failure fault; it can be seen that when the failure fault occurs, the method designed in this paper has good tracking performance. Similarly, Table 5 shows the MVTE and RMVSTE in Case 3. Figures 18-21 show the curves of the 
TABle 4: The MVTE and RMSVTE in Case 2.

\begin{tabular}{|c|c|c|c|c|}
\hline Types of error & Proposed scheme & TBSC scheme & DSC scheme & SMC scheme \\
\hline MVTE of G\#1 & $3.4536 e^{-06}$ & $7.6832 e^{-06}$ & $2.4130 e^{-05}$ & $8.3619 e^{-06}$ \\
\hline MVTE of G\#2 & $3.2387 e^{-06}$ & $1.5550 e^{-05}$ & $2.7959 e^{-05}$ & $6.8147 e^{-06}$ \\
\hline RMSVTE of G\#1 & $2.9299 e^{-06}$ & $5.8961 e^{-06}$ & $1.8058 e^{-05}$ & $5.5876 e^{-06}$ \\
\hline RMSVTE of G\#2 & $2.7118 e^{-06}$ & $1.0816 e^{-05}$ & $2.0317 e^{-05}$ & $5.6189 e^{-06}$ \\
\hline
\end{tabular}

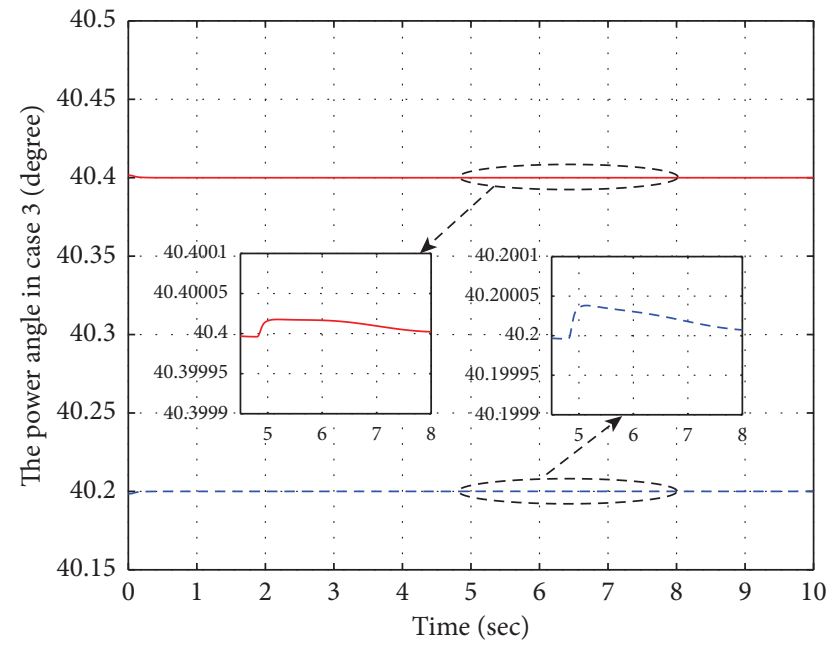

— The power angle of generator 1

- - - The power angle of generator 2

FIgURE 18: The power angles $\delta_{i}, i=1,2$, of the two generators in Case 3.

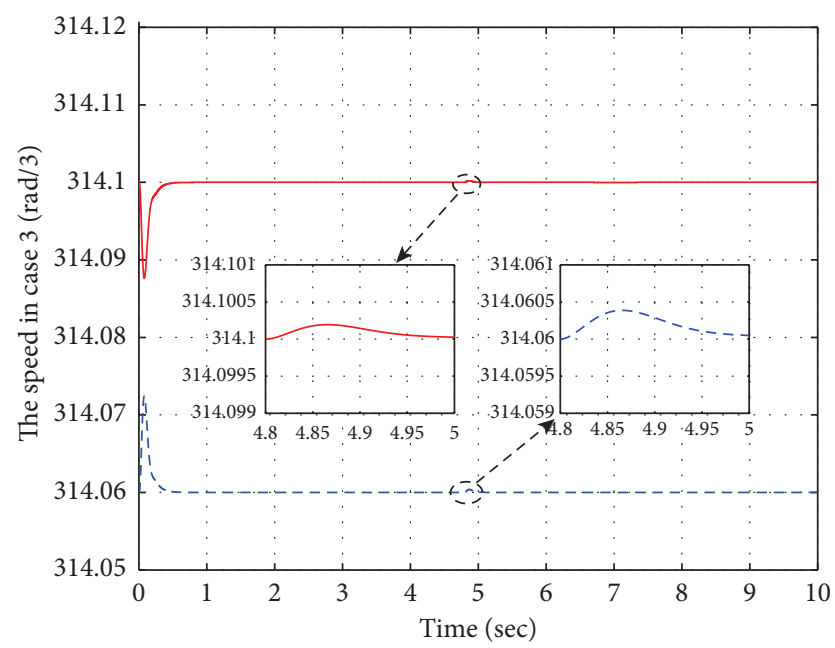

- The speed of generator 1

- - - The speed of generator 2

Figure 19: The rotated speeds $\omega_{i}, i=1,2$, of the two generators in Case 3.

power angles $\delta_{1}, \delta_{2}$, the rotated speeds $\omega_{1}, \omega_{2}$, the electrical powers $P_{e 1}, P_{e 2}$, and the control inputs $u_{1}, u_{2}$ of the excitation system under the case that the failure fault occurred at

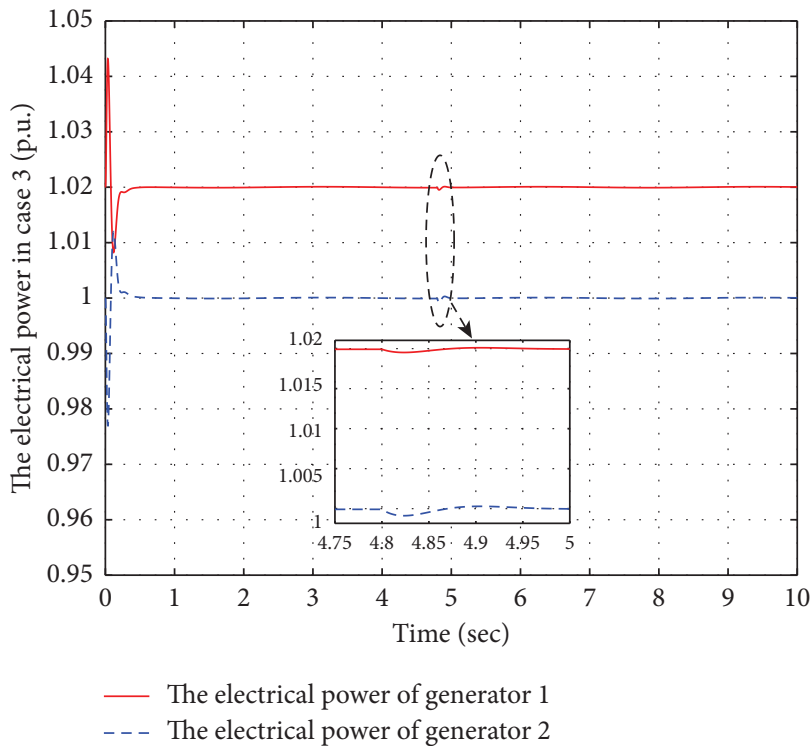

Figure 20: The electrical powers $P_{e i}, i=1,2$, of the two generators in Case 3.

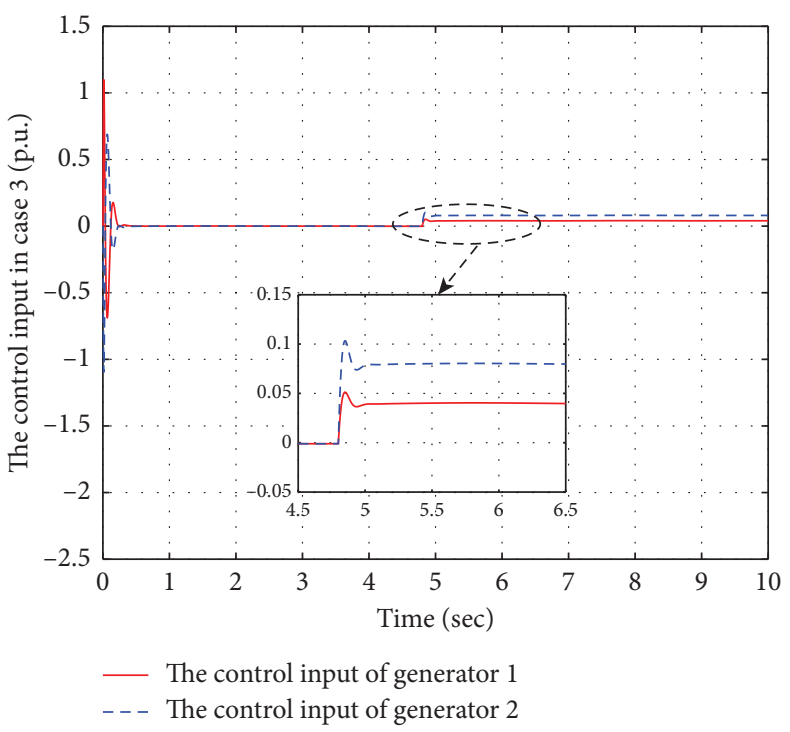

FIgURE 21: The control inputs $u_{i}, i=1,2$, of the two generators in Case 3.

$t=4.8 \mathrm{~s}$, respectively. Figures 22 and 23 illustrate the curves of the accessing voltages $V_{m 1}, V_{m 2}$ and the control inputs $u_{B 1}, u_{B 2}$ of SVC in the third case. 


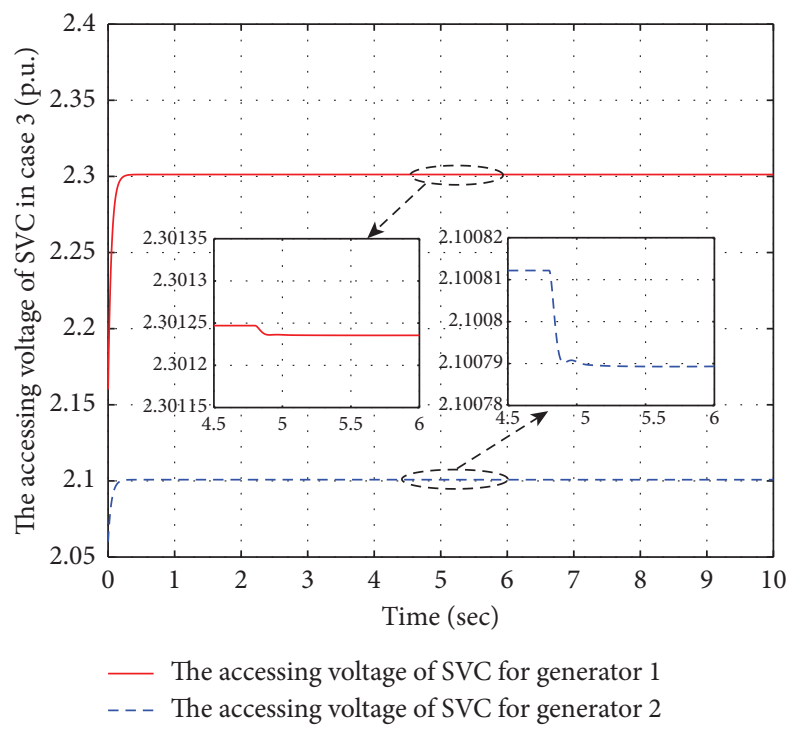

FIgURE 22: The accessing voltages $V_{m i}, i=1,2$, of the SVC for the two generators in Case 3.

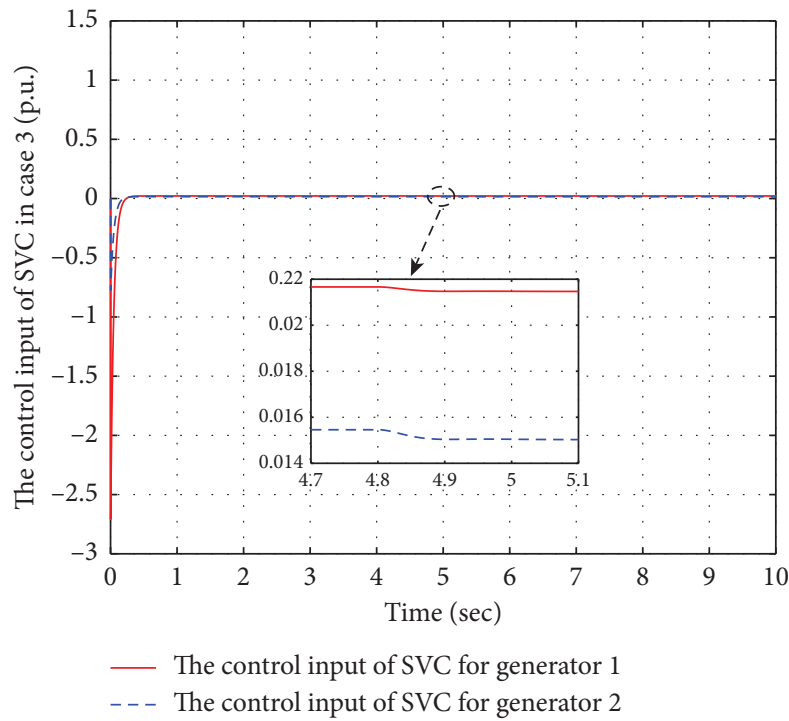

FIgURE 23: The control inputs $u_{B i}, i=1,2$, of the SVC in Case 3.

TABle 5: The MVTE and RMSVTE in Case 3.

\begin{tabular}{|c|c|c|c|c|}
\hline Types of error & Proposed scheme & TBSC scheme & DSC scheme & SMC scheme \\
\hline MVTE of G\#1 & $5.7220 e^{-06}$ & $4.8496 e^{-04}$ & $2.2845 e^{-04}$ & $2.8019 e^{-04}$ \\
\hline MVTE of G\#2 & $8.2102 e^{-06}$ & $2.5091 e^{-03}$ & $5.0814 e^{-04}$ & $5.6473 e^{-04}$ \\
\hline RMSVTE of G\#1 & $5.2248 e^{-06}$ & $4.8282 e^{-04}$ & $2.2052 e^{-04}$ & $2.7854 e^{-04}$ \\
\hline RMSVTE of G\#2 & $7.6584 e^{-06}$ & $2.5137 e^{-03}$ & $4.9848 e^{-04}$ & $5.6299 e^{-04}$ \\
\hline
\end{tabular}

\section{Conclusion}

In this paper, the method of combining adaptive dynamic surface with integral sliding mode fault-tolerant control is proposed to solve the excitation control problem of multimachine infinite-bus power systems with SVC by considering parameter uncertainties, external disturbances, and actuator failure. Applying the RBFNNs to approximate the unknown nonlinear function not only overcomes the uncertainty of the model but also reduces the computational 
burden. The designed controller solves the "explosion of complexity" problem of the traditional backstepping method and makes the tracking error converge to zero in a limited time, thereby improving the steady-state tracking accuracy of the system, while ensuring that the system still has good stability after the failure. Simulation results show the effectiveness of the proposed control algorithm. Future work will focus on the design of a disturbance observer based adaptive output feedback control scheme for multimachine power systems by introducing a fixed-time control method to improve the robustness of the system.

\section{Appendix}

Proof of Theorem 1. The time derivative of $V$ is as follows:

$$
\dot{V}=\dot{V}_{i 1}+\dot{V}_{i 2}+\dot{V}_{i 3}+\dot{V}_{i 4}+\sum_{i=1}^{n} y_{i 2 e} \dot{y}_{i 2 e}+\sum_{i=1}^{n} y_{i 3 e} \dot{y}_{i 3 e},
$$

$V_{i 1}=\frac{1}{2} \sum_{i=1}^{n} z_{i 1}^{2}$

The time derivative of $V_{i 1}$ is

$$
\dot{V}_{i 1}=\sum_{i=1}^{n} z_{i 1} \dot{z}_{i 1}
$$

By Formula (29), (T2.2), (T2.4), and (A.3), it can be obtained that

$$
\dot{V}_{i 1}=\sum_{i=1}^{n} z_{i 1}\left(z_{i 2}+y_{i 2 e}-c_{i 1} z_{i 1}\right) .
$$

By using Young's inequalities, we have

$$
\begin{aligned}
z_{i 1} z_{i 2} & \leq \frac{1}{2} z_{i 1}^{2}+\frac{1}{2} z_{i 2}^{2}, \\
z_{i 1} y_{i 2 e} & \leq \frac{1}{2} z_{i 1}^{2}+\frac{1}{2} y_{i 2 e}^{2} .
\end{aligned}
$$

Substitute (A.5) into (A.4); then, one has

$$
\begin{aligned}
& \dot{V}_{i 1} \leq \sum_{i=1}^{n}\left[-\left(c_{i 1}-1\right) z_{i 1}^{2}+\frac{1}{2} z_{i 2}^{2}+\frac{1}{2} y_{i 2 e}^{2}\right], \\
& V_{i 2}=\sum_{i=1}^{n}\left(\frac{1}{2 g_{i 2}} z_{i 2}^{2}+\frac{1}{2 r_{i 2}} \widetilde{v}_{i 2}^{2}\right) .
\end{aligned}
$$

Then, the time derivative of $V_{i 2}$ is

$$
\begin{aligned}
\dot{V}_{i 2} & =\sum_{i=1}^{n}\left(\frac{1}{g_{i 2}} z_{i 2} \dot{z}_{i 2}+\frac{1}{r_{i 2}} \widetilde{v}_{i 2} \dot{\vec{v}}_{i 2}\right) \\
& =\sum_{i=1}^{n}\left[z_{i 2}\left(-x_{i 3}+\frac{1}{g_{i 2}}\left(f_{i 2}\left(\bar{x}_{i 2}\right)+d_{i 1}-\dot{x}_{i 2 d}\right)\right)+\frac{1}{r_{i 2}} \widetilde{v}_{i 2} \dot{\hat{v}}_{i 2}\right] .
\end{aligned}
$$

Here, the RBF neural network is used to approximate unknown function $\left(1 / g_{i 2}\right)\left(f_{i 2}\left(\bar{x}_{i 2}\right)+d_{i 1}-\dot{x}_{i 2 d}\right)$ :

$$
\frac{1}{g_{i 2}}\left(f_{i 2}\left(\bar{x}_{i 2}\right)+d_{i 1}-\dot{x}_{i 2 d}\right)+\frac{1}{2} z_{i 2}=W_{i 2}^{* T} \varepsilon_{i 2}\left(\xi_{i 2}\right)+\sigma_{i 2}^{*},
$$

where $\xi_{i 2}=\left(x_{i 1}, x_{i 2}, x_{i 2 d}\right) \in R^{3},\left|\sigma_{i 2}^{*}\right| \leq \sigma_{i 2 m}$. According to Young's inequalities, there are

$$
z_{i 2} W_{i 2}^{* T} \varepsilon_{i 2}\left(\xi_{i 2}\right) \leq \frac{1}{2} z_{i 2}^{2} \varepsilon_{i 2}^{T} \varepsilon_{i 2} v_{i 2}^{*}+\frac{1}{2} z_{i 2} \sigma_{i 2}^{*} \leq \frac{1}{2} z_{i 2}^{2}+\frac{1}{2} \sigma_{i 2 m}^{2}
$$

with $\sigma_{i 2 m}$ being the upper boundary of the approximation error. Substituting (A.9) and (A.10) into (A.8), we can obtain that

$$
\dot{V}_{i 2} \leq \sum_{i=1}^{n}\left[z_{i 2}\left(-x_{i 3}+\frac{z_{i 2} \varepsilon_{i 2}^{T} \varepsilon_{i 2} v_{i 2}^{*}}{2}\right)+\frac{1}{2}+\frac{1}{2} \sigma_{i 2 m}^{2}+\frac{1}{r_{i 2}} \widetilde{v}_{i 2} \dot{\hat{v}}_{i 2}\right] \text {. }
$$

Substituting (T2.5) and (T2.6) into (A.11), one has

$$
\dot{V}_{i 2} \leq \sum_{i=1}^{n}\left[z_{i 2}\left(-z_{i 3}-y_{i 3 e}-c_{i 2} z_{i 2}\right)+\frac{1}{2}+\frac{1}{2} \sigma_{i 2 m}^{2}-\lambda_{i 2} \widetilde{v}_{i 2} \widehat{v}_{i 2}\right] \text {. }
$$

By using Young's inequalities, one has

$$
-z_{i 2} y_{i 3 e} \leq \frac{1}{2} z_{i 2}^{2}+\frac{1}{2} y_{i 3 e}^{2}
$$

Substituting (A.13) into (A.12), we can obtain that

$$
\begin{aligned}
& \dot{V}_{i 2} \leq \sum_{i=1}^{n}\left[-\left(c_{i 2}-\frac{1}{2}\right) z_{i 2}^{2}-z_{i 2} z_{i 3}+\frac{1}{2} y_{i 3 e}^{2}+\frac{1}{2}+\frac{1}{2} \sigma_{i 2 m}^{2}-\lambda_{i 2} \widetilde{v}_{i 2} \widehat{v}_{i 2}\right], \\
& V_{i 3}=\sum_{i=1}^{n}\left(\frac{1}{2 g_{i 3}} S_{i 3}^{2}+\frac{1}{2 \rho_{g i 3}} \widetilde{\theta}_{g i 3}^{2}+\frac{1}{2 r_{i 3}} \widetilde{v}_{i 3}^{2}\right) .
\end{aligned}
$$


Then, the time derivative of $V_{i 3}$ is

$$
\begin{aligned}
\dot{V}_{i 3} & =\sum_{i=1}^{n}\left(\frac{1}{g_{i 3}} S_{i 3} \dot{S}_{i 3}+\frac{1}{\rho_{g i 3}} \tilde{\theta}_{g i 3} \dot{\tilde{\theta}}_{g i 3}+\frac{1}{r_{i 3}} \widetilde{v}_{i 3} \dot{\tilde{v}}_{i 3}\right) \\
& =\sum_{i=1}^{n}\left[S_{i 3}\left(u_{i}+\frac{1}{g_{i 3}}\left(f_{i 3}\left(\bar{x}_{i 3}\right)-\dot{x}_{i 3 d}+d_{i 2}+F_{i}+y_{i}(\delta, \omega)\right)+\frac{k_{i 3}}{g_{i 3}} z_{i 3}\right)+\frac{1}{\rho_{g i 3}} \widetilde{\theta}_{g i 3} \dot{\hat{\theta}}_{g i 3}+\frac{1}{r_{i 3}} \widetilde{v}_{i 3} \dot{\hat{v}}_{i 3}\right] \\
& \leq \sum_{i=1}^{n}\left[S_{i 3}\left(u_{i}+\frac{1}{g_{i 3}}\left(f_{i 3}\left(\bar{x}_{i 3}\right)-\dot{x}_{i 3 d}+d_{i 2}+F_{i}+\sum_{j=1}^{n} \delta_{j i}\left(\left|x_{i 1}\right|,\left|x_{i 2}\right|\right)\right) \theta_{g i 3}^{*} \cdot k_{i 3} \cdot z_{i 3}\right)+\frac{1}{\rho_{g i 3}} \widetilde{\theta}_{g i 3} \dot{\hat{\theta}}_{g i 3}+\frac{1}{r_{i 3}} \widetilde{v}_{i 3} \dot{\hat{v}}_{i 3}\right],
\end{aligned}
$$

where $\sum_{j=1}^{n} \delta_{j i}\left(\left|x_{i 1}\right|,\left|x_{i 2}\right|\right)=\sum_{j=1}^{n}\left(\gamma_{i 1 j}\left|\delta_{j}\right|+\gamma_{i 2}\left|\omega_{j}\right|\right)$. Here, the RBF neural network is used to approximate unknown function $\left(1 / g_{i 3}\right)\left(f_{i 3}\left(\bar{x}_{i 3}\right)--\dot{x}_{i 3 d}+d_{i 2}+F_{i}+\sum_{j=1}^{n} \delta_{j i}\left(\left|x_{i 1}\right|,\left|x_{i 2}\right|\right)\right)$ with

$$
\left.\frac{1}{g_{i 3}}\left(f_{i 3}\left(\bar{x}_{i 3}\right)\right)+\sum_{j=1}^{n} \delta_{j i}\left(\left|x_{i 1}\right|,\left|x_{i 2}\right|\right)-\dot{x}_{i 3 d}+d_{i 2}+F_{i}\right)+\frac{1}{2} S_{i 3}=W_{i 3}^{* T} \varepsilon_{i 3}\left(\xi_{i 3}\right)+\sigma_{i 3}^{*},
$$

where $\xi_{i 3}=\left(x_{i 1}, x_{i 2}, x_{i 3}, x_{i 3 d}\right) \in R^{4},\left|\sigma_{i 3}^{*}\right| \leq \sigma_{i 3 m}$. According to Young's inequalities, there are

$$
S_{i 3} W_{i 3}^{* T} \varepsilon_{i 3}\left(\xi_{i 3}\right) \leq \frac{1}{2} S_{i 3}^{2} \varepsilon_{i 3}^{T} \varepsilon_{i 3} v_{i 3}^{*}+\frac{1}{2} S_{i 3} \sigma_{i 3}^{*} \leq \frac{1}{2} S_{i 3}^{2}+\frac{1}{2} \sigma_{i 3 m}^{2},
$$

with $\sigma_{i 3 m}$ being the upper boundary of the approximation error. Substituting (A.17) and (A.18) into (A.16), we can obtain that

$$
\dot{V}_{i 3} \leq \sum_{i=1}^{n}\left[S_{i 3}\left(u_{i}+\frac{v_{i 3}^{*} \varepsilon_{i 3}^{T} \varepsilon_{i 3} S_{i 3}}{2}+\theta_{g i 3}^{*} \cdot k_{i 3} \cdot z_{i 3}\right)+\frac{1}{2}+\frac{1}{2} \sigma_{i 3 m}^{2}+\frac{1}{\rho_{g i 3}} \tilde{\theta}_{g i 3} \dot{\hat{\theta}}_{g i 3}+\frac{1}{r_{i 3}} \widetilde{v}_{i 3} \dot{\hat{v}}_{i 3}\right] .
$$
has

Similarly, substituting (T2.10)-(T2.12) into (A.19), one

$$
\begin{aligned}
\dot{V}_{i 3} & \leq \sum_{i=1}^{n}\left(-c_{i 3} S_{i 3}^{2}+\frac{1}{2}+\frac{1}{2} \sigma_{i 3 m}^{2}-\delta_{i 3} \widetilde{\theta}_{g i 3} \widehat{\theta}_{g i 3}-\lambda_{i 3} \widetilde{v}_{i 3} \widehat{v}_{i 3}-\eta\left|S_{i 3}\right|\right), \\
V_{i 4} & =\sum_{i=1}^{n}\left(\frac{1}{2 g_{i 4}} z_{i 4}^{2}+\frac{1}{2 r_{i 4}} \widetilde{v}_{i 4}^{2}\right) .
\end{aligned}
$$

Then, the time derivative of $V_{i 4}$ is

$$
\begin{aligned}
\dot{V}_{i 4} & =\sum_{i=1}^{n}\left(\frac{1}{g_{i 4}} z_{i 4} \dot{z}_{i 4}+\frac{1}{r_{i 4}} \widetilde{v}_{i 4} \dot{\tilde{v}}_{i 4}\right) \\
& =\sum_{i=1}^{n}\left[z_{i 4}\left(u_{B i}^{\prime}+\frac{1}{g_{i 4}}\left(f_{i 4}\left(\bar{x}_{i 4}\right)-\dot{V}_{\text {refi }}\right)\right)+\frac{1}{r_{i 4}} \widetilde{v}_{i 4} \dot{\hat{v}}_{i 4}\right] .
\end{aligned}
$$

Similar to the above steps, the RBF neural network is used to approximate unknown function $\left(1 / g_{i 4}\right)\left(f_{i 4}\left(\bar{x}_{i 4}\right)-\right.$ $\dot{V}_{\text {refi }}$ ) with

$$
\frac{1}{g_{i 4}}\left(f_{i 4}\left(\bar{x}_{i 4}\right) \dot{V}_{\text {refi }}\right)+\frac{1}{2} z_{i 4}=W_{i 4}^{* T} \varepsilon_{i 4}\left(\xi_{i 4}\right)+\sigma_{i 4}^{*},
$$

where $\quad \xi_{i 4}=\left(x_{i 1}, x_{i 2}, x_{i 3}, x_{i 4}, V_{\text {refi }}\right) \in R^{5},\left|\sigma_{i 4}^{*}\right| \leq \sigma_{i 4 m}$. According to Young's inequalities, there are

$$
z_{i 4} W_{i 4}^{* T} \varepsilon_{i 4}\left(\xi_{i 4}\right) \leq \frac{1}{2} z_{i 4}^{2} \varepsilon_{i 4}^{T} \varepsilon_{i 4} v_{i 4}^{*}+\frac{1}{2} z_{i 4} \sigma_{i 4}^{*} \leq \frac{1}{2} z_{i 4}^{2}+\frac{1}{2} \sigma_{i 4 m}^{2}
$$

with $\sigma_{i 4 m}$ being the upper boundary of the approximation error. Substituting (A.23) and (A.24) into (A.22), we can obtain that

$$
\dot{V}_{i 4} \leq \sum_{i=1}^{n}\left[z_{i 4}\left(u_{B i}^{\prime}+\frac{v_{i 4}^{*} \varepsilon_{i 4}^{T} \varepsilon_{i 4} S_{i 4}}{2}\right)+\frac{1}{2}+\frac{1}{2} \sigma_{i 4 m}^{2}+\frac{1}{r_{i 4}} \widetilde{v}_{i 4} \dot{\widehat{v}}_{i 4}\right] .
$$


Substituting (T2.14) and (T2.15) into (A.25), one has

$$
\dot{V}_{i 4} \leq \sum_{i=1}^{n}\left(-c_{i 4} z_{i 4}^{2}+\frac{1}{2}+\frac{1}{2} \sigma_{i 4 m}^{2}-\lambda_{i 4} \widetilde{v}_{i 4} \widehat{v}_{i 4}\right),
$$

and consider the sets

$$
\begin{aligned}
& \Upsilon_{1}:=\left\{\left(x_{i 1 d}, \dot{x}_{i 1 d}, \ddot{x}_{i 1 d}\right): x_{i 1 d}^{2}+\dot{x}_{i 1 d}^{2}+\ddot{x}_{i 1 d}^{2} \leq B_{i 0}\right\}, \\
& \Upsilon_{2}:=\left\{\sum_{k=1}^{4} V_{i k}+\sum_{i=1}^{n} \frac{1}{2} y_{i 2 e}^{2}+\sum_{i=1}^{n} \frac{1}{2} y_{i 3 e}^{2} \leq p\right\} .
\end{aligned}
$$

The continuous functions $B_{i 2}$ and $B_{i 3}$ have maximums in the compact set $\Upsilon_{1} \times \Upsilon_{2}$. According to Young's inequalities, we have the following inequalities:

$$
\begin{aligned}
& \left|y_{i 2 e} B_{i 2}\right| \leq \frac{y_{i 2 e}^{2} B_{i 2}^{2}}{2 \mu}+\frac{\mu}{2} \leq \frac{y_{i 2 e}^{2} M_{i 2}^{2}}{2 \mu}+\frac{\mu}{2}, \\
& \left|y_{i 3 e} B_{i 3}\right| \leq \frac{y_{i 3 e}^{2} B_{i 3}^{2}}{2 \mu}+\frac{\mu}{2} \leq \frac{y_{i 3 e}^{2} M_{i 3}^{2}}{2 \mu}+\frac{\mu}{2},
\end{aligned}
$$

where $\mu$ is any positive constant and $M_{i 2}$ and $M_{i 3}$ are the maximums of $B_{i 2}$ and $B_{i 3}$, respectively. According to Young's inequalities, we have

$$
\begin{gathered}
-\lambda_{i 2} \widetilde{v}_{i 2} \widehat{v}_{i 2} \leq-\frac{\lambda_{i 2}}{2} \widetilde{v}_{i 2}^{2}+\frac{\lambda_{i 2}}{2} v_{i 2}^{* 2}, \\
-\lambda_{i 3} \widetilde{v}_{i 3} \widehat{v}_{i 3} \leq-\frac{\lambda_{i 3}}{2} \widetilde{v}_{i 3}^{2}+\frac{\lambda_{i 3}}{2} v_{i 3}^{* 2}, \\
-\lambda_{i 4} \widetilde{v}_{i 4} \widehat{v}_{i 4} \leq-\frac{\lambda_{i 4}}{2} \widetilde{v}_{i 4}^{2}+\frac{\lambda_{i 4}}{2} v_{i 4}^{* 2}, \\
-\delta_{i 3} \widetilde{\theta}_{g i 3} \widehat{\theta}_{g i 3} \leq-\frac{\delta_{i 3}}{2} \widetilde{\theta}_{g i 3}^{2}+\frac{\delta_{i 3}}{2} \theta_{g i 3}^{* 2} .
\end{gathered}
$$

Substituting (33), (34), and (A.6), as well as (A.14), (A.20), and (A.26) into (A.1), it follows that

$$
\dot{V} \leq \sum_{i=1}^{n}\left[\begin{array}{c}
-\left(c_{i 1}-1\right) z_{i 1}^{2}-\left(c_{i 2}-1\right) z_{i 2}^{2}-z_{i 2} z_{i 3}-c_{i 3} S_{i 3}^{2}-c_{i 4} z_{i 4}^{2}+\frac{1}{2} y_{i 2 e}^{2}+\frac{1}{2} y_{i 3 e}^{2} \\
+\frac{3}{2}+\frac{1}{2} \sigma_{i 2 m}^{2}+\frac{1}{2} \sigma_{i 3 m}^{2}+\frac{1}{2} \sigma_{i 4 m}^{2}-\lambda_{i 2} \widetilde{v}_{i 2} \widehat{v}_{i 2}-\lambda_{i 2} \widetilde{v}_{i 2} \widehat{v}_{i 2}-\lambda_{i 2} \widetilde{v}_{i 2} \widehat{v}_{i 2} \\
-\delta_{i 3} \tilde{\theta}_{g i 3} \widehat{\theta}_{g i 3}+y_{i 2 e}\left(-\frac{y_{i 2 e}}{\tau_{i 2}}+B_{i 2}\right)+y_{i 3 e}\left(-\frac{y_{i 3 e}}{\tau_{i 3}}+B_{i 3}\right)
\end{array}\right] .
$$

From (A.30), we can know that if $z_{i 3}$ converges to zero,

Substituting (A.28) and (A.29) into (A.30), it follows that $-z_{i 2} z_{i 3}$ will be eliminated. The integral sliding surface is designed to ensure that $z_{i 3}$ converges to zero in a finite time.

$$
\dot{V} \leq \sum_{i=1}^{n}\left[\begin{array}{c}
-\left(c_{i 1}-1\right) z_{i 1}^{2}-\left(c_{i 2}-1\right) z_{i 2}^{2}-c_{i 3} S_{i 3}^{2}-c_{i 4} z_{i 4}^{2}+y_{i 2 e}^{2}\left(\frac{1}{2}-\frac{1}{\tau_{i 2}}+\frac{M_{i 2}^{2}}{2 \mu}\right) \\
+y_{i 3 e}^{2}\left(\frac{1}{2}-\frac{1}{\tau_{i 3}}+\frac{M_{i 3}^{2}}{2 \mu}\right)+\mu+\frac{3}{2}+\frac{1}{2} \sigma_{i 2 m}^{2}+\frac{1}{2} \sigma_{i 3 m}^{2}+\frac{1}{2} \sigma_{i 4 m}^{2}-\frac{\lambda_{i 2}}{2} \widetilde{v}_{i 2}^{2} \\
-\frac{\lambda_{i 3}}{2} \widetilde{v}_{i 3}^{2}-\frac{\lambda_{i 4}}{2} \widetilde{v}_{i 4}^{2}-\frac{\delta_{i 3}}{2} \widetilde{\theta}_{g i 3}^{2}+\frac{\lambda_{i 2}}{2} v_{i 2}^{* 2}+\frac{\lambda_{i 3}}{2} v_{i 3}^{* 2}+\frac{\lambda_{i 4}}{2} v_{i 4}^{* 2}+\frac{\delta_{i 3}}{2} \theta_{g i 3}^{* 2}
\end{array}\right] .
$$

Let 


$$
\begin{aligned}
& \frac{1}{\tau_{i 2}} \geq \frac{1}{2}+\frac{M_{i 2}^{2}}{2 \mu}+a_{0}, \\
& \frac{1}{\tau_{i 3}} \geq \frac{1}{2}+\frac{M_{i 3}^{2}}{2 \mu}+a_{0},
\end{aligned}
$$

where $a_{0}$ is a positive design parameter. Substituting (A.32) and (A.33) into (A.31), one has

$$
\dot{V} \leq \sum_{i=1}^{n}\left[\begin{array}{c}
-\left(c_{i 1}-1\right) z_{i 1}^{2}-\left(c_{i 2}-1\right) z_{i 2}^{2}-c_{i 3} S_{i 3}^{2}-c_{i 4} z_{i 4}^{2} \\
-a_{0} y_{i 2 e}^{2}-a_{0} y_{i 3 e}^{2}-\frac{\lambda_{i 2}}{2} \widetilde{v}_{i 2}^{2}-\frac{\lambda_{i 3}}{2} \widetilde{v}_{i 3}^{2}-\frac{\lambda_{i 4}}{2} \widetilde{v}_{i 4}^{2}-\frac{\delta_{i 3} \widetilde{\theta}_{g i 3}^{2}}{2}
\end{array}\right]+C^{*},
$$

with

$$
C^{*}=\sum_{i=1}^{n}\left[\mu+\frac{3}{2}+\frac{1}{2} \sigma_{i 2 m}^{2}+\frac{1}{2} \sigma_{i 3 m}^{2}+\frac{1}{2} \sigma_{i 4 m}^{2}+\frac{\lambda_{i 2}}{2} v_{i 2}^{* 2}+\frac{\lambda_{i 3}}{2} v_{i 3}^{* 2}+\frac{\lambda_{i 4}}{2} v_{i 4}^{* 2}+\frac{\delta_{i 3}}{2} \theta_{g i 3}^{* 2}\right] .
$$

Here, $a_{0}$ satisfies

$$
a_{0} \leq \min \left\{g_{\min }\left(c_{i 1}-1\right), g_{\min }\left(c_{i 2}-1\right), c_{i 3}, c_{i 4}, \frac{r_{i 2} \lambda_{i 2}}{2}, \frac{r_{i 3} \lambda_{i 3}}{2}, \frac{r_{i 4} \lambda_{i 4}}{2}, \frac{\rho_{g i 3} \delta_{i 3}}{2}\right\}
$$

Then there is

$$
\dot{V} \leq-2 a_{0} V+C^{*} .
$$

By selecting $a_{0}$ to make $a_{0} \geq\left(C^{*} / 2 p\right)$ established, when $V=p, \dot{V} \leq 0$. So $V \leq p$ is an invariant set; that is, for all $t>0, V(t) \leq p$ if $V(0) \leq p$. The solution of inequality (A.37) is

$$
0 \leq V \leq \frac{C^{*}}{2 a_{0}}+\left(V(0)-\frac{C^{*}}{2 a_{0}}\right) e^{-2 a_{0} t} .
$$

Obviously, all error signals in the closed-loop system are semiglobally uniformly bounded within the compact set below.

$$
\Theta=\left\{\left(z_{i 1}, z_{i 2}, z_{i 3}, z_{i 4}, \widetilde{v}_{i 2}, \widetilde{v}_{i 3}, \widetilde{v}_{i 4}, \tilde{\theta}_{g i 3}, y_{i 2 e}, y_{i 3 e}\right): V \leq \frac{C^{*}}{2 a_{0}}\right\} .
$$

It implies that the compact set $\Theta$ can be arbitrarily small by adjusting parameters $c_{i 1}, c_{i 2}, c_{i 3}, c_{i 4}, r_{i 2}, r_{i 3}, r_{i 4}$, $\lambda_{i 2}, \lambda_{i 3}, \lambda_{i 4}, k_{i 3}, \delta_{i 3}, \rho_{g i 3}$. This completes the proof of Theorem 1 .

\section{Data Availability}

The data used to support the findings of this study are available from the corresponding author upon request.

\section{Conflicts of Interest}

The authors declare that there are no conflicts of interest regarding the publication of this article.

\section{Acknowledgments}

This work was supported in part by the NSF of China under Grants 61673101 and 61304015, the Natural Science
Foundation of Jilin Province under Grants 20180201009SF and 20180101069JC, the Thirteenth Five-Year Science Research Plan of Jilin Province under Grant JJKH20200119KJ, and the Jilin Technological Innovation Development Plan under Grant 201831719.

\section{References}

[1] Y. Wang, G. Guo, and D. J. Hill, "Robust decentralized nonlinear controller design for multimachine power systems," Automatica, vol. 33, no. 9, pp. 1725-1733, 1997.

[2] T. K. Roy, M. A. Mahmud, W. Shen, and A. M. T. Oo, "Nonlinear adaptive coordinated controller design for multimachine power systems to improve transient stability," IET Generation, Transmission \& Distribution, vol. 10, no. 13, pp. 3353-3363, 2016.

[3] Y. Wan, J. Zhao, and G. M. Dimirovski, "Robust adaptive control for a single-machine infinite-bus power system with an SVC," Control Engineering Practice, vol. 30, pp. 132-139, 2014.

[4] X. Zhang, B. Li, G. Zhu, X. Chen, and M. Zhou, "Decentralized adaptive quantized excitation control for multi-machine power systems by considering the line-transmission delays," IEEE Access, vol. 6, pp. 61918-61933, 2018.

[5] Y. Guo, D. J. Hill, and Y. Wang, "Nonlinear decentralized control of large-scale power systems," Automatica, vol. 36, no. 9, pp. 1275-1289, 2000.

[6] P. Zhao, W. Yao, J. Wen, L. Jiang, S. Wang, and S. Cheng, "Improved synergetic excitation control for transient stability enhancement and voltage regulation of power systems," International Journal of Electrical Power \& Energy Systems, vol. 68, pp. 44-51, 2010.

[7] G. Zhu, L. Nie, Z. Lv, L. Sun, X. Zhang, and C. Wang, "Adaptive fuzzy dynamic surface sliding mode control of large-scale power systems with prescribe output tracking performance," ISA Transactions, vol. 99, pp. 305-321, 2020.

[8] H. M. Soliman, H. A. Yousef, R. Al-Abri, and K. A. ElMetwally, "Decentralized robust saturated control of power 
systems using reachable sets," Complexity, vol. 2018, Article ID 2563834, 12 pages, 2018.

[9] G. Gurrala and I. Sen, "Power system stabilizers design for interconnected power systems," IEEE Transactions on Power Systems, vol. 25, no. 2, pp. 1042-1051, 2010.

[10] J. Zuo, Y. Li, D. Shi, and X. Duan, "Simultaneous robust coordinated damping control of power system stabilizers (PSSS), static var compensator (SVC) and doubly-fed induction generator power oscillation dampers (DFIG pods) in multimachine power systems," Energies, vol. 10, no. 4, p. 565, 2017.

[11] Q. Lu, Y. Sun, Z. Xu, and T. Mochizuki, "Decentralized nonlinear optimal excitation control," IEEE Transactions on Power Systems, vol. 11, no. 4, pp. 1957-1962, 1996.

[12] Y. Li, S. Qiang, X. Zhuang, and O. Kaynak, "Robust and adaptive backstepping control for nonlinear systems using RBF neural networks," IEEE Transactions on Neural Networks, vol. 15, no. 3, pp. 693-701, 2004.

[13] D. Wang and J. Huang, "Neural network-based adaptive dynamic surface control for a class of uncertain nonlinear systems in strict-feedback form," IEEE Transactions on Neural Networks, vol. 16, no. 1, pp. 195-202, 2005.

[14] G. Lai, Z. Liu, Y. Zhang, X. Chen, and C. L. Philip Chen, "Robust adaptive fuzzy control of nonlinear systems with unknown and time-varying saturation," Asian Journal of Control, vol. 17, no. 3, pp. 791-805, 2015.

[15] J. Peng and R. Dubay, "Adaptive fuzzy backstepping control for a class of uncertain nonlinear strict-feedback systems based on dynamic surface control approach," Expert Systems with Applications, vol. 120, pp. 239-252, 2019.

[16] Y. Feng, X. Yu, and F. Han, "On nonsingular terminal slidingmode control of nonlinear systems," Automatica, vol. 49, no. 6, pp. 1715-1722, 2013.

[17] A. Nasiri, S. Kiong Nguang, and A. Swain, "Adaptive sliding mode control for a class of mimo nonlinear systems with uncertainties," Journal of the Franklin Institute, vol. 351, no. 4, pp. 2048-2061, 2014.

[18] M. Jouini, S. Dhahri, and A. Sellami, "Combination of integral sliding mode control design with optimal feedback control for nonlinear uncertain systems," Transactions of the Institute of Measurement and Control, vol. 41, no. 5, pp. 1331-1339, 2019.

[19] A. Bonfiglio, F. Delfino, M. Invernizzi, A. Perfumo, and R. Procopio, "A feedback linearization scheme for the control of synchronous generators," Electric Power Components and Systems, vol. 40, no. 16, pp. 1842-1869, 2012.

[20] R. Yan, Z. Dong, T. Saha, and R. Majumder, "Power system transient stability enhancement with an adaptive control scheme using backstepping design," in Proceedings of the 2007 IEEE Power Engineering Society General Meeting, pp. 1-8, IEEE, Tampa, FL, USA, June 2007.

[21] T. K. Roy, M. A. Mahmud, W. Shen, A. M. T. Oo, and M. E. Haque, "Robust nonlinear adaptive backstepping excitation controller design for rejecting external disturbances in multimachine power systems," International Journal of Electrical Power \& Energy Systems, vol. 84, pp. 76-86, 2017.

[22] X. Zhang, Y. Wang, C. Wang, C.-Y. Su, Z. Li, and X. Chen, "Adaptive estimated inverse output-feedback quantized control for piezoelectric positioning stage," IEEE Transactions on Cybernetics, vol. 49, no. 6, pp. 2106-2118, 2018.

[23] X. Zhang, B. Li, X. Chen, Z. Li, Y. Peng, and C.-Y. Su, "Adaptive implicit inverse control for a class of discrete-time hysteretic nonlinear systems and its application," IEEE/ASME Transactions on Mechatronics, vol. 25, no. 4, pp. 2112-2122, 2020.
[24] M. Shahriari-kahkeshi, "Anti-disturbance dynamic surface control scheme for a class of uncertain nonlinear systems with asymmetric dead-zone nonlinearity," ISA Transactions, vol. 81, pp. 86-95, 2018.

[25] D. Swaroop, J. K. Hedrick, P. P. Yip, and J. C. Gerdes, "Dynamic surface control for a class of nonlinear systems," IEEE Transactions on Automatic Control, vol. 45, no. 10, pp. 1893-1899, 2000.

[26] X. Zhang, C. Liu, J. Wang, and Y. Lin, "Adaptive dynamic surface control for generator excitation control system," Mathematical Problems in Engineering, vol. 2014, Article ID 481936, 11 pages, 2014.

[27] G. Zhu, S. Wang, L. Sun, W. Ge, and X. Zhang, "Output feedback adaptive dynamic surface sliding mode control for quadrotor UAVS with tracking error constraints," Complexity, vol. 2020, Article ID 8537198, 23 pages, 2020.

[28] M. Mahmud, H. Pota, M. Aldeen, and M. Hossain, "Partial feedback linearizing excitation controller for multimachine power systems to improve transient stability," IEEE Transactions on Power Systems, vol. 29, no. 2, pp. 561-571, 2013.

[29] Y. Mi, Y. Fu, C. Wang, and P. Wang, "Decentralized sliding mode load frequency control for multi-area power systems," IEEE Transactions on Power Systems, vol. 28, no. 4, pp. 4301-4309, 2013.

[30] B. Jiang, H. R. Karimi, Y. Kao, and C. Gao, "A novel robust fuzzy integral sliding mode control for nonlinear semimarkovian jump T-S fuzzy systems," IEEE Transactions on Fuzzy Systems, vol. 26, no. 6, pp. 3594-3604, 2018.

[31] G. Zhu, L. Nie, M. Zhou, X. Zhang, L. Sun, and C. Zhong, "Adaptive fuzzy dynamic surface control for multi-machine power system based on composite learning method and disturbance observer," IEEE Access, vol. 8, pp. 1-13, 2020.

[32] L. Li and L. Yao, "Discrete-time 2-order sliding mode faulttolerant tracking control for nongaussian nonlinear stochastic distribution control systems with missing measurements," Complexity, vol. 2020, Article ID 9704861, 13 pages, 2020.

[33] X. Liu and Y. Han, "Decentralized multi-machine power system excitation control using continuous higher-order sliding mode technique," International Journal of Electrical Power \& Energy Systems, vol. 82, pp. 76-86, 2016.

[34] X. Zhang, X. Chen, G. Zhu, and C.-Y. Su, "Output feedback adaptive motion control and its experimental verification for time-delay nonlinear systems with asymmetric hysteresis," IEEE Transactions on Industrial Electronics, vol. 67, no. 8, pp. 6824-6834, 2020.

[35] S. Benahdouga, D. Boukhetala, F. Boudjema, R. Khenfer, and M. Meddad, "Decentralized adaptive sliding mode exciter control of power systems," International Review of Automatic Control, vol. 5, no. 6, pp. 790-797, 2012.

[36] P. K. Ray, S. R. Paital, A. Mohanty, F. Y. S. Eddy, and H. B. Gooi, "A robust power system stabilizer for enhancement of stability in power system using adaptive fuzzy sliding mode control," Applied Soft Computing, vol. 73, pp. 471-481, 2018.

[37] Y. Yu, C. Zhang, and M. Zhou, "Narmax model-based hysteresis modeling of magnetic shape memory alloy actuators," IEEE Transactions on Nanotechnology, vol. 19, pp. 1-4, 2020.

[38] Z. Li, J. Shan, and U. Gabbert, "Dynamics modeling and inversion-based synchronized model predictive control for a fabry-perot spectrometer," IEEE/ASME Transactions on Mechatronics, vol. 24, no. 4, pp. 1818-1828, 2019.

[39] Y. Li and S. Tong, "Adaptive fuzzy control with prescribed performance for block-triangular- structured nonlinear 
systems," IEEE Transactions on Fuzzy Systems, vol. 26, no. 3, pp. 1153-1163, 2017.

[40] H. T. Hassan, I. A. Khan, and M. U. Ali, "Design and implementation of synchronous generator excitation control system using fuzzy logic controller," American Journal of Engineering Research (AJER), vol. 2, no. 12, pp. 75-82, 2013.

[41] Z. Li and J. Shan, "Inverse compensation based synchronization control of the piezo-actuated fabry-perot spectrometer," IEEE Transactions on Industrial Electronics, vol. 64, no. 11, pp. 8588-8597, 2017.

[42] Y. Li, L. Liu, and G. Feng, "Robust adaptive output feedback control to a class of non-triangular stochastic nonlinear systems," Automatica, vol. 89, pp. 325-332, 2018.

[43] X. Zhang, Y. Wang, G. Zhu et al., "Compound adaptive fuzzy quantized control for quadrotor and its experimental verification," IEEE Transactions on Cybernetics, 2020.

[44] X. Zhang, Y. Wang, X. Chen et al., "Decentralized adaptive neural approximated inverse control for a class of large-scale nonlinear hysteretic systems with time delays," IEEE Transactions on Systems, Man, and Cybernetics: Systems, vol. 49, no. 12, pp. 2424-2437, 2019.

[45] C. Zhang, Y. Yu, Y. Wang, and M. Zhou, "Takagi-sugeno fuzzy neural network hysteresis modeling for magnetic shape memory alloy actuator based on modified bacteria foraging algorithm," International Journal of Fuzzy Systems, vol. 22, no. 4, pp. 1314-1329, 2020.

[46] W. L. Li, "Nonlinear coordinated control for SVC and generator excitation based on sliding mode dynamic surface method," Applied Mechanics and Materials, vol. 229-231, pp. 2302-2305, 2012.

[47] F. Shi, J. Wang, and G. Xue, "Coordinated excitation and SVC control based on Hamilton theory for improving transient stability of multi-machine power system," Electric Power Automation Equipment, vol. 32, no. 10, pp. 48-52, 2012.

[48] Y. Liu, J. Li, Q. Ding, and B. Chu, "Energy-based coordinated nonlinear control of synchronous generator and static var compensator," International Journal of Electrical Power \& Energy Systems, vol. 43, no. 1, pp. 131-140, 2012.

[49] L. Zhang, A. Zhang, Z. Ren, G. Li, C. Zhang, and J. Han, "Hybrid adaptive robust control of static var compensator in power systems," International Journal of Robust and Nonlinear Control, vol. 24, no. 12, pp. 1707-1723, 2014.

[50] S. Jain, F. Khorrami, and B. Fardanesh, "Adaptive nonlinear excitation control of power systems with unknown interconnections," IEEE Transactions on Control Systems Technology, vol. 2, no. 4, pp. 436-446, 1994.

[51] L.-Y. Sun, S. Tong, and Y. Liu, “Adaptive backstepping sliding mode $h_{\infty}$ control of static var compensator," IEEE Transactions on Control Systems Technology, vol. 19, no. 5, pp. 1178-1185, 2010.

[52] Y. Wan and F. Milano, "Nonlinear adaptive excitation control for structure preserving power systems," IEEE Transactions on Power Systems, vol. 33, no. 3, pp. 3107-3117, 2017.

[53] T. K. Roy, M. A. Mahmud, W. Shen, and A. M. T. Oo, "Nonlinear adaptive excitation controller design for multimachine power systems with unknown stability sensitive parameters," IEEE Transactions on Control Systems Technology, vol. 25, no. 6, pp. 2060-2072, 2016.

[54] X. Jiao, Y. Sun, and T. Shen, "Adaptive controller design for a synchronous generator with unknown perturbation in mechanical power," International Journal of Control, Automation, and Systems, vol. 3, no. 2, pp. 308-314, 2005. 